\title{
How Does Labor MobiLity Affect Income Convergence?
}

\author{
Jordan Rappaport
}

This Version: July 2000

RWP 99-12

\author{
Research Division \\ Federal Reserve Bank of Kansas City
}

Jordan Rappaport is an economist at the Federal Reserve Bank of Kansas City. The author would like to thank Alberto Alesina, Larry Ball, Robert Barro, Chris Foote, Ed Glaeser, Jill Holman, Matt Kahn, David Laibson, Philip Lane, John McHale, Jong-Wha Lee, Dani Rodrik, Jeff Sachs, David Weil and seminar participants at the Federal Reserve Bank of Kansas City, the 1999 Federal Reserve System Regional Meeting, Harvard University, Brown University, the University of Maryland, and the University of Wisconsin for advice and feedback. He would also like to thank the Center for International Development at Harvard University and the National Science Foundation for financial support. The views expressed in this paper are those of the author and do not necessarily reflect the views of the Federal Reserve Bank of Kansas City or the Federal Reserve System.

Rappaport e-mail: jordan.m. rappaport@kc.frb.org 


\begin{abstract}
The neoclassical growth model is extended to allow for mobile labor. Following a negative shock to a small economy's capital stock, capital and labor frictions effect an equilibrium transition path during which wages remain below their steady-state level. Outmigration directly contributes to faster income convergence but also creates a disincentive for gross capital formation. The net result is that across a wide range of calibrations, the speed of income convergence is relatively insensitive to the degree of labor mobility.
\end{abstract}

Keywords: Economic Growth, Income Convergence, Factor Mobility, Migration. JEL Classifications: O41, F43, J61 


\section{Introduction}

How does labor mobility affect income convergence? Intuitively, individuals' moving in search of higher wages might be expected to increase the speed at which per capita income is equilibrated across regions. But empirical research has failed to find a link between labor mobility and the speed of income convergence. What the intuition misses is that the exit of labor from poorer economies lowers the return to capital there and so slows gross capital formation. Extending the neoclassical growth framework to allow for labor mobility, this paper argues that the disincentive effect of labor flows on gross capital formation roughly offsets their direct effect on capital intensity. Numerical results across a wide range of calibrations show that the resulting net effect of labor mobility on the speed of income convergence is small.

The extended neoclassical growth framework developed herein premises a large integrated macroeconomy made up of numerous small open economies across which there is high labor mobility. In a long run steady state, capital intensities and hence wages must be equal across these small constituent economies. But following a negative shock to a single constituent economy's capital stock, frictions - in the form of an installation cost to capital proportional to the rate of gross investment and an analogous moving cost proportional to the rate of net migration - effect an extended equilibrium transition path during which local wages will be below their steady-state level. Rather than labor mobility, the main determinant of the speed of income convergence is the degree of capital mobility as measured by the cost of installing capital.

A first subsidiary result is that the speed of income convergence varies considerably in a neighborhood very close to the system steady state; hence measuring the speed of convergence right at the steady state based on a linearization proves a misleading metric. A second subsidiary result is that steady-state population density is history dependent; such hysteresis follows from consumption smoothing and does not depend on any non-neoclassical assumptions such as increasing returns to scale. Both a highly varying speed of convergence and a history-dependent steady state follow generically from a growth system with multiple state (i.e., non-jumping) variables.

The paper proceeds as follows. Section 2 discusses related literature including empirical estimates of the link between labor mobility and income convergence. Section 3 develops 
the extended neoclassical growth framework. Section 4 discusses the qualitative features of the time paths of population, income, and housing prices following a negative shock to a single constituent economy's capital stock; across a wide range of calibrations, varying the degree of labor mobility has a large effect on the time paths of population and housing prices but only a small effect on the time path of income. Section 5 concludes.

\section{Background}

A natural starting point is to formally define "the speed of convergence":

$$
\Lambda\left(\log y(t)-\log y^{*}(t)\right) \equiv \frac{-\frac{\mathrm{d}}{\mathrm{d} t}\left(\log y(t)-\log y^{*}(t)\right)}{\log y(t)-\log y^{*}(t)}
$$

Here, the numerator measures the rate at which income, $y(t)$, moves towards its contemporary steady-state value, $y^{*}(t)$. The denominator measures the distance of income from this steady state. As defined, the speed of convergence will be positive so long as income is indeed moving towards its steady state.

In the special case where the speed of convergence does not depend on income's distance from its steady state, i.e., $\Lambda(\cdot)=\lambda$, the convergence speed definition can be rewritten,

$$
\frac{\frac{\mathrm{d}}{\mathrm{d} t} y(t)}{y(t)}=-\lambda\left(\log y(t)-\log y^{*}(t)\right)+\frac{\frac{\mathrm{d}}{\mathrm{d} t} y^{*}(t)}{y^{*}(t)}
$$

Assuming $\log y^{*}$ to be measured by $\mathbf{x}^{\prime} \boldsymbol{\beta}$, a linear combination of exogenous attributes, then by regressing growth rates on initial income and a vector of such attributes, a constant speed of convergence will be measured by the coefficient on initial income (making an adjustment for the fact that the above equations hold in continuous time whereas crosssectional growth empirics are based on discrete time observations). Barro and Sala-i-Martin (1991, 1992, 1995) compare cross-sectional income growth regressions from several different geographies including U.S. states, European regions, and Japanese prefectures. Presumably the degree of labor mobility varies between these geographies. But the estimated speeds of convergence from the growth regressions are nearly identical across these geographies and are approximately the same as the estimated speed of convergence from cross-country growth regressions (approximately 2 percent per year). Looking across U.S. counties over the period 1960 to 1990, Rappaport (1999a) obtains similar estimates for the speed of income convergence. ${ }^{1}$

\footnotetext{
${ }^{1}$ Barro and Sala-i-Martin estimate the speed of convergence using the nonlinear form, $\left(\frac{1}{T}\right)$.
} 
One explanation for the similar convergence estimates is simply that (1) is misspecified. For instance, the numerical results below show the speed of convergence to vary greatly as a small open economy approaches its steady state. Other problems with interpreting the coefficient on initial income as measuring the speed of convergence include endogeneity of the controls measuring steady-state income, endogeneity of initial income, and mismeasurement of initial income. (Islam, 1985; Caselli, Esquivel, and Lefort, 1996; Ades and Glaeser, 1994. For a more general critique of cross-sectional growth empirics, see Durlauf and Quah, 1998). Using a high frequency panel technique which allows the speed of convergence to vary across observations, Evans and Karras (1996) and Evans (1997) indeed find substantially higher speeds of convergence for U.S. states than for a group of 54 countries.

Barro and Sala-i-Martin argue that the lack of effect of labor mobility on convergence speed is consistent with neoclassical growth theory based on empirical estimates which show only a very small response of labor flows to wage differentials; essentially, labor mobility does not affect income convergence because labor is not very mobile. Looking at the relationship between net migration and initial wage levels for U.S. states for each decade, 1900 through 1990, Barro and Sala-i-Martin's highest estimate of labor mobility suggests that a 25 percent wage differential is necessary to induce a 1 percent rate of net migration.

Other researchers find an even smaller response of net migration to wage differentials. Hatton and Williamson (1998), for instance, estimate the sensitivity to relative real wages of emigration rates from various European countries during the late 19th and early 20th centuries; their baseline estimate suggests that it took more than a 400 percent wage differential to induce a 1 percent rate of emigration (Table 3.3, column 1); their highest esimate of labor mobility - from Ireland over the period 1878 to 1913 - suggests that it took a 53 percent real wage differential to induce a 1 percent rate of emigration (Table 5.2, column 2). Blanchard and Katz (1995) examining employment growth across U.S. states over the period 1950 to 1990 and Rappaport (1999a) examining net migration across U.S. counties over the period 1960 to 1990 find no consistent relationship between wage levels and population flows.

But the failure to find a strong relationship between wage levels and population flows $(\log y(t+T)-\log y(t))=\left(\frac{1}{T}\right) \cdot\left(1-e^{-\lambda T}\right)\left(\log y^{*}(t)-\log y(t)\right)+\frac{\frac{\mathrm{d}}{\mathrm{d} t} y^{*}(t)}{y^{*}(t)}$. Doing so is essentially the same as estimating (1) and then making the transformation $\lambda=-\frac{\log (1-\tilde{\lambda} T)}{T}$ where $\tilde{\lambda}$ is the negative of the linear coefficient on initial income. 
does not necessarily imply that labor is immobile. Rather, theory suggests that in addition to income, population flows are also driven by quality-of-life considerations (Rosen, 1979; Roback, 1982; Gyourko and Tracy, 1989, 1991; Rappaport, 1999b). Observed wage differences may be due to a locality's being away from its long run steady-state capital intensity; or they may simply be compensating for differing quality of life (e.g., due to weather, natural amenities, etc.). In the latter case, even with perfect labor mobility we would observe no correlation between wage levels and population flows.

Moreover, even after controlling for quality of life, theory suggests that population flows are driven by relative real wealth levels rather than relative wages. Wages denominated in terms of tradable output exaggerate differences in relative real wealth in at least three different ways. First is that individuals' consumption bundles include local nontradables (e.g., housing services) whose price level is likely to be proportional to local wages. Second is the convergence over time of wage levels as documented in Barro and Sala-i-Martin (1991). Third is that relative real wealth includes not just labor wealth but also asset wealth; the higher the asset wealth of individuals, the lower the relative real wealth difference for a given difference in relative labor wealth.

In practice, of course, neither quality of life nor relative real wealth is observable. Hence the use of supposed exogenous attributes to measure the former and relative wages to proxy for the latter. Such a combination introduces still another downward bias in estimating the response of labor flows to income differentials. Attributes included to measure quality of life may also affect an economy's productivity; for instance, a coastal location may provide both recreational opportunities as well as inexpensive transport. Relative productivity levels, in turn, presumably underlie long run wealth differences. And so to the extent that observed wages fail to capture true wealth differences, the population response to wealth differences may be captured in part by a partial correlation of population flows with attributes meant to control for quality of life.

That it takes a 25 percent real wealth differential to induce a one percent rate of net migration across U.S. states seems implausible. And if labor is indeed reasonably mobile across localities, the Barro Sala-i-Martin explanation for the similar estimates of convergence speed across the various geographies falls short. Reinforcing this puzzle is the theoretical work of Braun (1993), which shows that near a steady state the speed of income convergence will equal the speed of population convergence (i.e., the speed at which population converges 
towards its steady state); hence we should expect the speed of income convergence to be directly proportional to the degree of labor mobility.

The disincentive effect of mobile labor on gross capital formation resolves the puzzle. The explanation is consistent with Braun's results in that the asymptotic speed of income convergence is indeed directly proportional to the degree of labor mobility. However, both theoretical and numerical results show that the asymptotic speed of convergence will hold only in a neighborhood extremely close to the system steady state. Beyond this neighborhood, a data generating process of the form (1) is essentially irrelevant.

\section{A Neoclassical Theory of Local Growth}

Extending the neoclassical growth model (Ramsey, 1928; Cass, 1965; Koopmans, 1965) to allow for labor mobility is essentially to model local economic growth. "Local" is meant to connote a small open economy within a larger integrated macroeconomy characterized by high labor mobility. A locality may correspond to a city or region within a nation state or even, as perhaps suggested by the European Union, to a nation state itself. Being small, a locality can take tradable output prices and interest rates as given; conditions within the locality itself determine local nontradable prices, local wage levels, and local population.

In a long run steady state, each of the localities which together make up the integrated macroeconomy must offer optimizing individuals an identical level of utility and optimizing firms an identical level of profits. This condition is exactly the same as the identifying assumption underlying the compensating wage differential literature (Rosen, 1979; Roback, 1982; Gyourko and Tracy, 1989, 1991). But frictions to labor and capital mobility effect an extended equilibrium transition path during which rents will be associated with living and owning installed capital in certain localities relative to others. Herein I will focus on the dynamics experienced by a single such locality while assuming that the integrated rest-ofworld economy is already at its steady state. The dynamics by which the overall system reaches a steady state thus remains an important question for future research.

A final change to the standard neoclassical setup is that, in addition to consumption of tradable output, individual utility is augmented to include consumption of a locally produced nontradable good. Herein, I simply assume a constant flow supply of the nontradable good; a natural interpretation is that it corresponds to housing services. To the extent that 
production of the tradable good is capital intensive relative to production of the nontradable good, nontradable consumption lessens the incentive for emigration from capital poor localities. Equally important, the inclusion of a fixed resource such as housing services captures that a locality is limited in scope; without a fixed resource constraint, all individuals and firms within the integrated macroeconomy end up locating in the locality with the highest productivity.

Various elements of the extended neoclassical growth theory already exist within the economics literature. In particular, Mueser and Graves (1995) contend that the instantaneous equating of utility and profits across localities assumed by static theories of locational choice is unrealistic; instead, they argue that population and firm locational movements must be proportional to utility and profit differentials. More formally, Braun (1993) introduces labor mobility into the neoclassical growth framework by assuming that labor flows are proportional to the difference in the net present value of labor income.

Though straightforward, the current model is a challenge to present due to the large number of associated variables and equations. Herein I highlight just the setup and the results; all derivations are available upon request. The remainder of this section is divided into seven subsections: individual utility functions and behavior, firm production functions and behavior, land price determination, characteristics of the integrated macroeconomy steady state, the decision by individuals to migrate, transitional dynamics, and the characteristics of the locality steady state.

\subsection{Individuals}

I assume a small open economy, $i$, inhabited by a continuum of individuals with collective mass $L_{i}(t)$. These individuals need not be identical; but if they are not, I must adopt a structure sufficient to allow for the admittance of a representative local agent. Herein, such structure is indeed present as are assumptions that insure that all locally-residing individuals are identical; per capita variables can thus be interpreted as pertaining either to a representative agent or to all local individuals.

A key difference from the standard neoclassical framework is that in addition to the consumption of private output goods, individuals also derive utility from the consumption of private housing services, $n_{i}(t)$. Lifetime utility is given by,

$$
U_{i}(t)=\int_{t}^{\infty}\left((1-\zeta) \log \left(c_{i}(s)\right)+\zeta \log \left(n_{i}(s)\right)\right) \mathrm{e}^{-\rho(s-t)} \mathrm{d} s
$$


As in the neoclassical model, individuals face an instantaneous asset accumulation constraint. To ease exposition, I assume absentee landlords. While such an assumption clearly maps poorly to actual local housing ownership, relaxing it just reinforces the present system's dynamics. With the output good as numeraire and $p_{i}(t)$ as the rental price of housing services, asset accumulation is given by,

$$
\frac{\mathrm{d}}{\mathrm{d} t} \operatorname{assets}_{i}(t)=r \cdot \operatorname{assets}_{i}(t)+w_{i}(t)-c_{i}(t)-p_{i}(t) n_{i}(t)
$$

Individuals face the lifetime budget constraint that the net present value of their output and housing-service consumption not exceed their current wealth which is itself the sum of their asset wealth and the net present value of their wages.

$$
\begin{gathered}
\int_{t}^{\infty}\left(c_{i}(s)+p_{i}(t) n_{i}(s)\right) e^{-r(s-t)} \mathrm{d} s \leq \text { total_wealth }_{i}(t) \\
\operatorname{total}_{\text {_wealth }}(t) \equiv \operatorname{assets}_{i}(t)+\text { labor_wealth }_{i}(t) \\
\text { labor_wealth }_{i}(t) \equiv \int_{t}^{\infty} w_{i}(s) \mathrm{e}^{-r(s-t)} \mathrm{d} s
\end{gathered}
$$

Setting up and solving for individuals' optimal behavior, at any point in time they will devote the fraction $\rho$ of their total wealth on current consumption; of this, they will spend the fraction $(1-\zeta)$ on the tradable output good and the remaining fraction $\zeta$ on housing services. The actual quantity of housing services consumed depends on its rental price, the level of which will be determined endogenously.

$$
\begin{gathered}
c_{i}(t)=\rho(1-\zeta) \text { total_wealth }_{i}(t) \\
n_{i}(t)=\frac{\rho \zeta \text { total_wealth }_{i}(t)}{p_{i}(t)}
\end{gathered}
$$

The additive separable utility form in (2) along with the optimal output and housing consumption functions, (5a) and (5b), allow for an easy decomposition of individuals' lifetime utility into a function, $f(\cdot)$, whose arguments are exogenous to locality $i$, along with elements that depend separably on individuals' wealth and the time path of local housing rental prices.

$$
\begin{aligned}
U_{i}(t) & =\mathrm{f}(\rho, \zeta, r)+\frac{\log \left(\text { total_wealth }_{i}(t)\right)}{\rho}-\zeta \int_{t}^{\infty} \log \left(p_{i}(s)\right) \mathrm{e}^{-\rho(s-t)} \mathrm{d} s \\
& =\mathrm{f}(\rho, \zeta, r)+U_{\text {wealth }, i}(t)+U_{\text {price }, i}(t)
\end{aligned}
$$

Since the economy-wide adding up constraint that the sum of individuals' asset wealth must equal the aggregate capital stock does not apply to our locality, it becomes necessary 
to track the evolution of local asset wealth. Assuming for the moment no effect on mean asset wealth from migration into or out of the locality, (3), (5a) and (5b) imply that per capita asset wealth evolves according to,

$$
\frac{\mathrm{d}}{\mathrm{d} t} \operatorname{assets}_{i}(t)=w_{i}(t)+(r-\rho) \operatorname{assets}_{i}(t)-\rho \cdot \text { labor_wealth }_{i}(t)
$$

As discussed below, I assume that anyone migrating into locality $i$ has the same contemporary asset wealth as the current mean in $i$ which implies that (7) will hold in equilibrium. ${ }^{2}$

\section{$3.2 \quad$ Firms}

Within the locality are a number of firms, each with access to a constant-returns-to-scale (CRS) production function. As CRS implies an indeterminate firm size, I write instead the aggregate local production function,

$$
Y_{i}(t)=A_{i}(t) K_{i}(t)^{\alpha}\left(L_{i}(t) \mathrm{e}^{x t}\right)^{1-\alpha}
$$

$A_{i}(t)$ and $x$ respectively capture locality-specific total productivity and the economy-wide rate of exogenous labor-augmenting technological progress. For the purpose of modeling income convergence, nothing is lost by assuming identical total factor productivity across localities and so henceforth I will drop the corresponding "i" subscript.

Output can be rewritten in intensive form based on the number of "effective" labor units as, ${ }^{3}$

$$
\hat{y}_{i}(t)=A(t) \widehat{k}_{i}(t)^{\alpha}
$$

A firm's objective is to maximize the net present value of its profits. Along the lines of Abel (1982) and Hayashi (1982), I assume an adjustment cost to installing capital. In particular, I specialize the average cost of installing capital to be a linear function of the rate of gross investment, $\frac{b_{K}}{2} \frac{I_{i}(t)}{K_{i}(t)}$. The parameter $b_{K}$ captures the magnitude of the capital installation cost. Letting $b_{K}$ go to zero captures a world in which capital can be costlessly

\footnotetext{
${ }^{2}$ The main importance of asset wealth is its role in determining local housing prices as shown in (11) below. Given the homothetic specification of utility in (2), what matters for housing prices is mean local asset wealth. Allowing for individuals with different levels of asset wealth, the evolution of mean asset wealth is the same as in (7) along with the addition of a term that captures the difference between current mean asset wealth and the asset wealth of current migrants.

${ }^{3}$ In general, lower case variables are meant to connote the per capita normalization of aggregate levels and "hatted" variables, the normalization by the level of labor-augmenting technological progress, $\mathrm{e}^{x t}$.
} 
installed and uninstalled. Firms face the dynamic constraint that the change in their level of capital stock is just the sum of their level of gross investment less capital depreciation. Local firms' dynamic optimization problem can be written in current-value Hamiltonian form as,

$$
\begin{aligned}
\mathrm{H}_{\mathrm{firms}, i}(t)= & A(t) K_{i}(t)^{\alpha}\left(L_{i}(t) \mathrm{e}^{x t}\right)^{1-\alpha}-w_{i}(t) L_{i}(t) \\
& -\left(1+\frac{b_{K}}{2} \frac{I_{i}(t)}{K_{i}(t)}\right) I_{i}(t)+q_{K, i}(t) \cdot\left(I_{i}(t)-\delta K_{i}(t)\right)
\end{aligned}
$$

The two choice variables are the firms' level of employment, $L_{i}(t)$, and their level of gross investment, $I_{i}(t) .{ }^{4}$ The co-state variable, $q_{K, i}(t)$, captures the current shadow value of the marginal unit of installed capital. That the production function, (8), is CRS and that the installation cost function depends only on the ratio $\frac{I_{i}(t)}{K_{i}(t)}$ together imply that this "marginal" $q$ in fact equals "average" $q$, the ratio of the value of total installed capital to its uninstalled replacement cost (Hayashi, 1982). The solution to (10) is standard and so is omitted.

\subsection{Housing Price Determination}

Local housing services are assumed to flow at the fixed aggregate rate, $N_{i}(t) .{ }^{5}$ With housingservice supply permanently fixed and population instantaneously fixed, mean per capita housing-service consumption, $n_{i}(t)$, must equal $\frac{N_{i}}{L_{i}(t)}$. The current rental price of housing services, $p_{i}(t)$, is just the price which realizes this level of housing-service demand. Using (5b) and the definition of total wealth, the price of housing services which clears the market can be written as,

$$
p_{i}(t)=\frac{\rho \zeta}{N_{i}} L_{i}(t) \cdot\left(\operatorname{assets}_{i}(t)+\text { labor_wealth }_{i}(t)\right)
$$

\footnotetext{
${ }^{4}$ Note that as expressed in (10), these are in fact aggregate locality- $i$ variables. Given the indeterminacy of scale associated with CRS production functions, the distinction is immaterial. Also, given the assumption that the local labor market clears, $L_{i}(t)$ is predetermined; what is not predetermined is the wage that will make firms willing to employ $L_{i}(t)$ units of labor.

${ }^{5}$ More realistically, housing services might be supposed to be produced using a locality's fixed supply of land combined with various amounts of other intermediate inputs. The inclusion of a housing-service production function is a priority for future research; for the moment the justification for a fixed supply of housing services is that it captures that housing-service production above some threshold level is doubtlessly characterized by a very high marginal cost.
} 
The sales price of housing services can then be calculated as the net present value of the housing service rental price:

$$
\operatorname{value}_{i}(t) \equiv \int_{t}^{\infty} p_{i}(s) \mathrm{e}^{-r(s-t)} \mathrm{d} s
$$

\subsection{Integrated Macroeconomy Steady State}

In contrast to locality $i$, the remaining rest-of-world economy is assumed to be in its long run steady state. That locality $i$ is small and the rest of the world is large allows for such a dichotomy. The row steady state is characterized by standard neoclassical results for a closed economy. Net borrowing among row individuals is zero and so mean row asset wealth must exactly equal the value of row installed capital, $\operatorname{assets}_{\text {row }}(t)=q_{K, \text { row }} k_{\text {row }}(t)$. The interest rate which effects such an equilibrium is given by the sum of individuals rate of time preference and the rate of technological progress, $r=\rho+x$. The equilibrium shadow value of capital, $q_{K, \text { row }}$, is exactly that which induces a rate of investment consistent with a constant level of capital per effective worker:

$$
q_{K, \text { row }}=1+(x+\delta) b_{K}
$$

The constancy in the steady state of system variables when normalized by the level of technology implies that each of these grows at the exogenous rate of technological progress without such a normalization:

$$
\frac{\frac{\mathrm{d}}{\mathrm{d} t} w_{\text {row }}(t)}{w_{\text {row }}(t)}=\frac{\frac{\mathrm{d}}{\mathrm{d} t} \text { labor_wealth }_{\text {row }}(t)}{\text { labor_wealth }_{\text {row }}(t)}=\frac{\frac{\mathrm{d}}{\mathrm{d} t} k_{\text {row }}(0 t)}{k_{\text {row }}(t)}=\frac{\frac{\mathrm{d}}{\mathrm{d} t} \operatorname{assets}_{\text {row }}(t)}{{\operatorname{assets_{\text {row}}}}(t)}=\frac{\frac{\mathrm{d}}{\mathrm{d} t} p_{\text {row }}(t)}{p_{\text {row }}(t)}=x
$$

\subsection{The Decision to Migrate}

Analogous to the installation cost associated with capital investment, I assume a labor mobility friction proportional to net population flow rates. To motivate this, consider rental prices for one-way do-it-yourself moving trucks. Supposing a net flow of individuals from East to West, demand for rental trucks will be high in the East while their supply will be high in the West. The higher the net flow west, the higher westbound prices need to be to equilibrate supply and demand. Conversely, companies may be willing to subsidize eastbound movers in order to redeploy their fleets. It is hard to imagine such moving prices effecting large frictions, and so the calibrations below will show results for net migration frictions which are "very small". 
Frictions proportional to the rate of net migration might arise from several other sources. For instance, relaxing the assumption of a fixed flow supply of housing services, housing stock could be modeled with an installation cost exactly the same as that for physical capital. While such a setup would admit discrete infinite-rate population flows immediately following shocks, additional net population flows would accompany transitional expansions and contractions of housing stock. Endogenizing the labor mobility friction is a priority for future research.

Of course, numerous other labor mobility frictions may arise which are not proportional to net flows. Large gross flows may increase costs by lengthening expected job search time. Alternatively, large gross flows may decrease costs by facilitating a thicker market for services demanded by movers (e.g., the very existence of one-way do-it-yourself rental truck companies). For departure-destination location pairs, information transmission may make costs decreasing in the sum over previous gross flows. Such alternative frictions are unlikely to be completely orthogonal to net flows, and therefore they may very well modify local growth dynamics. Even so, it seems quite reasonable to believe a "net" friction proportional to net population flows will remain. Again it is worth emphasizing that the numerical results below include calibrations with "very small" labor mobility frictions.

I model the labor mobility friction as a utility cost proportional to the net flow rates in both the departing and receiving locality. Letting arrows represent the direction of net migration, the utility cost can be formalized as,

$$
\begin{aligned}
& U_{i \rightarrow \text { row }}^{\text {cost }}=b_{L} \cdot\left(\frac{\frac{\mathrm{d}}{\mathrm{d} t} L_{\text {row }}(t)}{L_{\text {row }}(t)}-\frac{\frac{\mathrm{d}}{\mathrm{d} t} L_{i}(t)}{L_{i}(t)}\right)=-b_{L} \frac{\frac{\mathrm{d}}{\mathrm{d} t} L_{i}(t)}{L_{i}(t)} \\
& U_{\text {row } \rightarrow i}^{\text {cost }}=b_{L} \cdot\left(-\frac{\frac{\mathrm{d}}{\mathrm{d} t} L_{\text {row }}(t)}{L_{\text {row }}(t)}+\frac{\frac{\mathrm{d}}{\mathrm{d} t} L_{i}(t)}{L_{i}(t)}\right)=b_{L} \frac{\frac{\mathrm{d}}{\mathrm{d} t} L_{i}(t)}{L_{i}(t)}
\end{aligned}
$$

The second set of equalities follows from the largeness assumption about row. ${ }^{6}$

Modeling the labor friction as a utility cost rather than a wealth cost is done for analytical tractability. A wealth cost proportional to net flows will effect nearly identical dynamics as long as it rises at the rate of exogenous technological progress, for instance if costs were proportional to real wages. ${ }^{7}$ Indeed, the utility cost is calibrated based on the

\footnotetext{
${ }^{6}$ The flow out of or into row is just the negative of the flow into or out of $i$, and $L_{\text {row }}$ is an order of magnitude greater than $L_{i}$; as long as $\frac{\mathrm{d}}{\mathrm{d} t} L_{i}(t)$ is of the same order of magnitude as $L_{i}(t), \frac{\frac{\mathrm{d}}{\mathrm{d} t} L_{i}(t)}{L_{r} \text { ow }} \approx 0$.

${ }^{7}$ Assuming a wealth cost which rises at less than the rate of exogenous technological progress, labor mobility increases with time.
} 
relative wealth needed to induce a one percent rate of net migration. The only difference between a utility-based friction and a wealth-based friction is that under the former, individuals have the same asset wealth both prior to and after migrating whereas under the latter, individuals have a lower asset wealth after migrating. Assuming a wealth cost to net migration would actually increase the labor mobility friction in the sense that a larger labor wealth differential would be needed to induce any given rate of net migration.

In an equilibrium, the flow between $i$ and row must be such that the marginal migrant be indifferent between migrating or not. This will be the case when the utility cost associated with migrating exactly equals the incremental lifetime utility associated with living in the destination location. Defining $\mathrm{d} U_{i}(t)$ as the utility differential associated with living in $i$,

$$
\mathrm{d} U_{i}(t) \equiv U_{i}(t)-U_{\text {row }}(t)
$$

It follows that the rate of net migration into locality $i$ is given by,

$$
\frac{\frac{\mathrm{d}}{\mathrm{d} t} L_{i}(t)}{L_{i}(t)}=\frac{\mathrm{d} U_{i}(t)}{b_{L}}
$$

While all agents in both $i$ and row are assumed to be identical with regards to their inherent characteristics (there are no high-skilled or low-skilled individuals), where they may differ is with regards to their asset wealth; moreover this is a difference that they retain should they choose to migrate. Let $\mathrm{d} U_{i}(t)>0$ so that there is a positive utility differential associated with living in $i$ and hence a net migration flow from row to $i$. The largeness assumption on row obviates the need to distinguish between marginal and average migrants (i.e., row has a sufficient number of residents with any given asset wealth level that all time- $t$ migrants can be assumed to be identical). A "marginal migrant" from row into $i$ is assumed to have asset wealth equivalent to the contemporary mean in $i$. As all residents in $i$ are assumed to start with identical asset wealth prior to any shocks, the same definition works when there is a net flow from $i$ to row.

Consistent with Tiebout's (1956) hypothesis that migration sorts a heterogenous population into more homogenous sub-populations, migration in the present case sorts individuals according to their asset wealth. A possible justification is that in the real world, zoning laws place limits on the quantity of housing services that individuals can buy; having the same asset wealth as current residents, in-migrants desire the same quantity of housing services. ${ }^{8}$ Note that in an important sense this assumption of Tiebout wealth sorting binds:

\footnotetext{
${ }^{8}$ More problematic is reconciling such a zoning explanation with the modeling of in-migrants as raising
} 
the lower an individual's asset wealth, the greater their utility gain for a given increase in labor wealth. ${ }^{9}$ And so when utility is (temporarily) higher in $i$ than in row due to higher labor wealth, it is those individuals in row with the lowest asset wealth who have the greatest incentive to migrate.

The main result emphasized herein — the insensitivity of the speed of income convergence to the degree of labor mobility - does not depend on such Tiebout wealth sorting. Driving the insensitivity result is the disincentive effect on gross capital formation caused by the exit of labor from low-capital-intensity localities; this exit occurs regardless of the specific assumption made with respect to the asset wealth of migrants. Nor does the history dependence of steady-state population density discussed below depend on Tiebout wealth sorting. So long as local residents can use asset wealth to smooth their consumption, local steady-state population density will depend on the history of local shocks. (Also see Appendix B.) Given the homothetic specification of individual utility, alternative assumptions on the asset wealth of migrants could be handled in a straightforward manner. ${ }^{10}$

In contrast, the nature of the history dependence (as opposed to its existence) closely depends on the assumed asset wealth of migrants. Such fragility suggests attaching little importance to the specifics of the history dependence described below. ${ }^{11}$

The utility differential associated with living in $i$ relative to row can be decomposed

aggregate demand for housing services thereby causing current residents to decrease their housing-service consumption (but not expenditure).

${ }^{9}$ To formalize this, just replace "assets $i(t)$ " in (17a) below with "assetsmigrant $(t)$ " and notice that $\frac{\partial \mathrm{d} U_{\text {wealth }, i}}{\partial \text { assets }_{\text {migrant }}}>0$ as labor_wealth ${ }_{i}>$ labor_wealth law $_{\text {row }}$.

${ }^{10}$ Assuming that migrants are those with asset wealth who stand to benefit most from a given move should strengthen the disincentive effect of labor mobility on gross capital formation. Following a negative capital shock (described below), out-migrants will be those local residents with the lowest asset wealth and hence the lowest housing consumption. Because low-asset-wealth migrants "free up" less housing than do migrants with mean asset wealth, a larger cumulative outflow should be needed to cause housing prices to fall sufficiently to effect a return migration. Return migrants will be characterized by high asset wealth and high housing consumption so that a smaller cumulative inflow should be needed to cause housing prices to return to their original level. As the value of installed capital is directly proportional to current and future population levels, both the larger outflow and the smaller inflow should further dampen gross capital formation.

${ }^{11}$ The scenario in the previous footnote "reverses" the characteristics of the new steady state: a negative capital shock causes a decrease in steady-state population density due to an increase in steady-state asset wealth. 
using (6b) where each of the right-hand-side terms is defined analogously to $\mathrm{d} U_{i}(t)$ :

$$
\mathrm{d} U_{i}(t)=\mathrm{d} U_{\text {wealth }, i}(t)+\mathrm{d} U_{\text {price }, i}(t)
$$

Using (6a) and the definition of total wealth, these in turn can be written as,

$$
\begin{gathered}
\mathrm{d} U_{\text {wealth }, i}(t)=\frac{1}{\rho} \log \left(\frac{\text { labor_wealth }_{i}(t)+\operatorname{assets}_{i}(t)}{\text { labor_wealth }_{\text {row }}(t)+\operatorname{assets}_{i}(t)}\right) \\
\mathrm{d} U_{\text {price }, i}(t)=\zeta \int_{t}^{\infty} \log \left(\frac{p_{\text {row }}(s)}{p_{i}(s)}\right) \mathrm{e}^{-\rho(s-t)} \mathrm{d} s
\end{gathered}
$$

The quotient in (17a) captures the relative wealth of a potential migrant between $i$ and row. As discussed above, migration implies a change only in labor wealth with asset wealth remaining the same.

\subsection{Dynamics}

The dynamic system can now be expressed as a system of seven differential equations in $\left\{L_{i}(t), \widehat{k}_{i}(t), \widehat{\operatorname{asset}}_{i}(t), q_{K, i}(t), d U_{\text {wealth }, i}(t), d U_{\text {price }, i}(t), \widehat{\operatorname{valu}}_{i}(t)\right\}$. The first three of these, $\left\{L_{i}(t), \widehat{k}_{i}(t)\right.$, and $\left.\widehat{\operatorname{asset}}_{i}(t)\right\}$, - are "state" variables which are instantaneously fixed (i.e., they can not "jump"). The remaining four, $\left\{q_{K, i}(t), d U_{\text {wealth }, i}(t), d U_{\text {price }, i}(t)\right.$, and $\left.\widehat{v a l u e}_{i}(t)\right\}$, are "co-state" variables which can jump, but only in reaction to unexpected system shocks. The dynamic system is mutually recursive with respect to all of the variables with the exception of $\widehat{\operatorname{valu}}_{i}(t)$; none of the remaining system variables depends on the evolution of $\widehat{\operatorname{value}}_{i}(t)$ and so it could be dropped from the system without further loss of information; I retain $\widehat{\operatorname{value}}_{i}(t)$ because it maps to a key local observable. The actual expressions for the differential equations are deferred until Appendix A.

Any remaining endogenous variables can be calculated from the contemporary values of these seven system variables along with the various exogenous parameters.

\subsection{Local Steady State}

The local steady state can be derived by setting each of the seven system differential equations just discussed, (A.1a) - (A.1g), equal to zero and solving for the state and co-state variables. The actual expressions are again deferred until Appendix A. The steady-state

values of two of these, $\left\{\widehat{k}_{i}(t), q_{K, i}(t)\right\}$, are determinate in that they can be expressed as a function of exogenous parameters alone. The remaining five system variables, $\left\{L_{i}(t)\right.$, 
$\widehat{\operatorname{asset}}_{i}(t), d U_{\text {wealth }, i}(t), d U_{\text {price }, i}(t)$, and $\left.\widehat{\operatorname{valu}}_{i}(t)\right\}$, collectively have one degree of freedom in the sense that in addition to the exogenous parameters, the steady-state value of one of these needs to be known to determine the steady-state values of the other four.

The "extra" degree of freedom results from the fact that the overall system is subject to history dependence. For the intuition on how this arises, consider two localities, $i$ and $j$, identical in all exogenous parameters, but having a different history of local development. In particular, at some point in the distant past $i$ experienced a "helicopter drop" of installed physical capital. At this same point in the distant past, $j$ experienced an "artillery drop" which destroyed a large portion of its installed capital base. (Thankfully, no one was injured.) The steady-state levels of labor income will be identical between the two localities. But during the transitions to their respective steady states, $i$ 's residents have high current relative to permanent income whereas $j$ 's residents have low current relative to permanent income. Consumption smoothing leads i's residents to accumulate but $j$ 's residents to decumulate asset wealth during the transition to the steady state. It immediately follows that in these steady states, $i$ 's residents have a higher asset wealth than $j$ 's residents. While the steady-state price of housing services will be identical between the two localities - if not, there would be an incentive to migrate - the higher asset wealth of $i$ 's residents means that they will be purchasing a higher steady-state quantity of housing services. With equal aggregate flows of housing services, this can only be if the population of $i$ is smaller than that of $j$.

The story should illustrate that the one degree of freedom with respect to the system variables in no the way implies that there is any possibility of "choice" over steady states (other than altering the exogenous parameters). On the contrary the system is fully determined; it is just that this determination is based both on the "static" exogenous parameters as well as the history of local shocks. Individuals' consumption smoothing serves as the underlying mechanism. ${ }^{12}$

But the story also illustrates that the nature of the history dependence is somewhat perverse: a "good" shock causes an economy's steady-state population to fall whereas a "bad" shock causes an economy's steady-state population to rise. Here, the key underlying mechanism is the assumed inelastic supply of housing services. With local size as measured

\footnotetext{
${ }^{12}$ So one way to remove such hysteresis would be to allow individuals to insure against geographically-based shocks.
} 
by housing stock fixed, local size as measured by population depends primarily on local income distribution. And local income distribution, in turn, depends primarily on modeling assumptions for which there is no obvious choice (e.g., the asset wealth of migrants, integer constraints on housing quantity consumption, the possibility of bidirectional gross labor flows). As mentioned above, the close dependence on assumptions of the nature of the hysteresis suggests attaching little importance to it. But such fragility does not extend to the existence of the hysteresis, a result which is robust across a wide range of assumptions.

\section{Factor Mobility and Income Convergence}

Numerical solutions to the local growth system richly characterize the time paths of population, income, and housing prices following a negative shock to a locality's capital stock. The speed at which income converges back towards its steady state turns out to depend mostly on the degree of capital mobility (i.e., the capital installation friction) and is relatively insensitive to the degree of labor mobility. This qualitative result is robust across a wide range of calibrations.

A "negative capital shock" is meant to connote any set of circumstances which leaves a locality with a low installed capital base relative both to the remainder of an integrated macroeconomy and to its own steady-state level. Literally interpreted, negative capital shocks might correspond to natural and man-made disasters. More metaphorically, negative capital shocks might correspond to changes in technology or the terms of trade which disproportionately affect the installed capital base of some localities relative to others but which do not fundamentally alter long run relative productivity: for instance, changes in manufacturing techniques in steel production on certain areas of the Midwest United States during the early 1980s.

\subsection{Representative Time Paths}

Figure 1 sketches the time paths of population, wages, land prices, and the speed of income convergence following a shock to a locality's capital stock which leaves wages at 60 percent of their steady-state level. Immediately following the shock (at time 0), population begins to rapidly flow out of the locality (Panel A). The decrease in local wages causes both the sales and rental price of land to discretly jump downward; following the shock the rental 
price of land continues to fall driven by the outflow of population (Panel C). Not shown is the large inflow of gross capital stock that the negative capital shock induces (due to an increase in the the marginal revenue product of capital and hence its shadow value). The population outflow and the capital inflow both tend to increase wages; higher wages along with lower housing service prices eventually reverse the population outflow. As population flows back into the locality, gross capital formation remains sufficiently positive to allow wages to continue to converge back towards their steady-state level. The sales and rental price of housing services also gradually return to their steady-state levels.

As laid out in the theory section above, the local growth system is characterized by history dependence. Following a negative capital shock, consumption smoothing causes individuals to decumulate assets. Along with the assumption of Tiebout wealth sorting, this decumulation implies that locality per capita asset wealth will be lower in the new steady state. As lower per capita asset wealth implies lower per capita demand for housing services, steady-state equilibrium in the land market requires a higher population than was present prior to the income shock. For the base calibration shown in Figure 1, immediately following a negative capital shock, population flows out of the locality at a 3.5 percent annual rate. From an initial level of exactly 1, population reaches a nadir of 0.858 after 12 years. Population returns to its original level approximately 54 years after the initial shock and continues to rise eventually reaching 1.058 in the new steady state. Per capita asset wealth in the new steady state is 0.447 of its pre-shock level (normalized for the level of labor-augmenting technology).

Wages rapidly converge to their pre-shock level. Immediately following the shock, the population outflow combined with the gross capital inflow combine to cause wages to grow at an 8.3 percent annual rate. ${ }^{13}$ In less than 6 years they have returned to 80 percent of their steady-state level; in just over 12 years they have returned to 90 percent of their steady-state level; and in approximately 40 years they have returned to 99 percent of their steady-state level. Note that at this 40-year benchmark, population and land prices remain substantially below their pre-shock levels (which for population applies a fortiori to its level relative to its new steady state).

Panel D illlustrates that the speed of income convergence as measured by the rate at

\footnotetext{
${ }^{13}$ Note that here and below, wages are measured relative to their row level which implicitly normalizes them by the level of labor augmenting technology.
} 
which income closes the log gap to its steady state varies considerably along the transition path. It steadily drops from $\Lambda=0.163$ immediately following the capital shock to $\Lambda=0.114$ after 10 years, $\Lambda=0.057$ after 40 years, and $\Lambda=0.040$ asymptotically. Measured at points based on income's distance to the steady-state rather than at points based on time elasped since the capital shock, the speed of convergence falls from $\Lambda=0.163$ when wages are at 60 percent of their steady-state level to $\Lambda=0.097$ when wages are at 95 percent of their steady-state level to $\Lambda=0.057$ when wages are at 99 percent of their steady-state level to $\Lambda=0.040$ at the steady state itself (i.e., within an $\epsilon$ neighborhood of it).

While a decreasing speed of convergence commonly characterizes neoclassical growth systems, in general the rate at which the speed falls off is decreasing as income approaches its steady state (i.e., the speed has a negative first but positive second derivative with respect to income). In the present case, a negative second derivative of convergence speed as income increases implies that the speed of convergence can vary considerably even in a neigborhood quite close to the steady state. For calibrations with lower labor mobility than in Figure 1 , the speed of convergence drops from rates near $\Lambda=0.09$ when wages are at 99 percent of their steady state to less than $\Lambda=0.01$ at the steady state itself. Indeed, measuring the speed of convergence only at the steady state, the local growth system appears to achieve a calibration that has proved elusive for the neoclassical growth model: a narrow capital share along with a low steady-state shadow value of capital and a slow speed of convergence; but examining the speed of income convergence at income levels more than negligably below the steady state, the slow speed of convergence disappears.

A varying speed of income convergence along with history dependence of the steady state turn out to be generic properties of growth systems with multiple state (i.e., "nonjumping") variables. For a growth system to be globally stable, the dimensionality of the steady state plus the dimensionality of the transition path to this must sum to the number of state variables. A steady state with dimensionality one or greater corresponds to history dependence. And Appendix B shows that for a transition path with dimensionality two or greater, even a linearization implies a varying speed of convergence (a similar point is made by Eichner and Turnovsky, 1999).

Given the way it varies, $\Lambda(\cdot)$ does not prove a very useful measure of convergence speed. Instead I will use wage levels at various benchmark times and the time to reach various benchmark wage levels as my main comparison metrics. 


\subsection{Base Calibration}

The representative time paths sketched in Figure 1 derive from a single calibration of a model with a large number of exogenous parameters. In exploring the qualitative robustness of the time paths with respect to variations in the levels of these exogenous parameters, a natural starting point is to try to choose "base" parameter values that allow the model to approximately match real world observables.

In general I have used parameter values which are the same as in Barro and Sala-iMartin (1995). As enumerated on the right hand side of Figure 1, these include the capital depreciation rate, $\delta=0.05$, the rate of time preference, $\rho=0.02$, and the rate of exogenous technological progress, $x=0.02$.

Barro and Sala-i-Martin include two parameterizations of the capital share, $\alpha$. A first narrow capital share parameterization, $\alpha=0.30$, corresponds to a literal interpretation of physical capital and approximately matches the share of national income accounted for by rental income, profits, and interest payments. Within a traditional neoclassical growth framework, a narrow capital share parameterization is associated with a speed of convergence that tends both to be "too high" and to decline rapidly as income approaches its steady state. A partial solution to both problems comes from assuming a broad capital share, for instance $\alpha=0.75$, corresponding to a more metaphorical interpretation of capital to include human capital. The solution is only partial, first because a broad concept of capital implies investment rates somewhat higher than we actually observe and, second, because a decreasing speed of convergence remains in the open-economy version of the neoclassical model (King and Rebello, 1993; Rappaport, 2000).

For the purposes of local growth theory, a broad capital share is especially problematic. To the extent that broad capital is interpreted as human capital, the appropriate friction would be the labor rather than the capital friction: that is that a qualitatively important difference between physical and human capital is the mobility of the latter. Even so, it is possible to argue for a broader share of fixed capital in output production than is implied

by the national income accounts. One possibility is that estimating the capital share using factor income fails to account for tax-financed public-sector capital (to the extent that it was debt-financed, the associated interest payments would contribute to the implied capital share). Another possibility is that human capital is in part locality-specific so that its adjustment may be more appropriately modeled by the capital rather than the labor 
friction. In the alternative calibration section below, I will consider the case of a moderately broad capital share, $\alpha=0.60$.

Unique to the local growth model is a parameter capturing the share of consumption expenditure devoted to housing services. A 20 percent housing share, $\zeta=0.20$, roughly matches the correponding figure from the U.S. national income accounts. As housing services proxy more generally for local nontradable goods (and to the extent that local housing prices may contribute to the final price facing consumers for locally sold tradable goods), this housing share is meant to be conservative. The main effect of raising the housing share parameter is to dampen the response to the capital shock. In the limit as the housing share approaches 1, the capital shock elicits no outmigration response (i.e., the rental price of housing services falls to exactly the level which allows individuals to continue to consume the same quantity of housing services). Alternatively, in the limit as the housing share approaches zero, capital deepening fails to elicit a reverse migration back to the locality.

Given the motivating question, how does factor mobility affect income convergence, the parameters which are inherently of the most interest are those that govern the capital installation and net migration frictions $-b_{K}$ and $b_{L}$. As a starting point, I map these friction parameters to more intuitive measures of mobility. In particular, for given rates of depreciation and exogenous technological progress, the capital friction maps one-to-one with the steady-state shadow value of capital, $q_{K}^{*}$. Similarly, for a given rate of time preference, the labor friction maps one-to-one with the relative wealth necessary to induce a one percent annual rate of net migration, $\omega$; from (15) and (17a), $\omega=\exp \left(0.01 \cdot \rho \cdot b_{L}\right)$.

Aggregate empirical timeseries suggest that the shadow value of capital tends to remain relatively close to one (Summers, 1981; Blanchard, Rhee, and Summers, 1993). Even without labor mobility, however, neoclassical growth models calibrated with steady-state shadow values of capital near one tend to have implausibly high rates of income convergence. For instance, in the closed-economy analog to the local growth model (i.e., with no labor mobility and with local savings financing local investment), a steady-state shadow value of capital $q_{K}^{*}=1.14$ implies a steady-state speed of income convergence $\Lambda=0.091$. In the open-economy version of the model (i.e., with no labor mobility but with the ability to borrow and lend at an exogenous interest rate), it implies a steady-state speed of income convergence $\Lambda=0.175$. While the closed-economy convergence rate is consistent with some recent panel-data estimates (Islam, 1995, Caselli, LeFort, and Esquival, 1995), the open- 
economy convergence rate is not. To make matters worse, predicted convergence rates tend to be much higher for countries with incomes even moderately below their steady-state levels (i.e., the speed of convergence is falling into the steady state as discussed above). The effect of labor mobility on convergence speed when there is "high capital mobility" is pursued as an alternative calibration below. ${ }^{14} 15$

To allow for slower income convergence, I choose for a base calibration, a higher steadystate shadow value of capital, $q_{K}^{*}=1.56$. This level of capital mobility is consistent with empirical estimates by Barnett and Sakellaris (1998). Using panel data on firms over the period 1960 to 1987 , they report a median average value of installed capital, $q=1.23$ which rises to $q=1.79$ after adjusting for investment tax incentives. Even so, the speed of convergence as measured at the steady state in traditional neoclassical growth models remains somewhat high $(\Lambda=0.067$ and $\Lambda=0.093$ for the closed- and open-economy versions, respectively). Hence the alternative calibrations section below also considers the case of a considerably higher steady-state shadow value of capital, $q_{K}^{*}=3.24$ (which implies closed- and open-economy steady-state speeds of convergence $\Lambda=0.048$ and $\Lambda=0.059$ ).

For benchmarking the labor mobility parameter, the background section above outlines a number of reasons to believe that traditional empirical estimates of the migration response to current income differentials may greatly understate labor mobility. That it takes on the order of a 25 percent real wealth premium to induce a 1 percent rate of net migration within an integrated macroeconomy (such as the United States in the late 20th century) does not seem plausible.

An alternative approach which suggests that labor is indeed highly mobile is proposed by Gallin (1999). He focuses on the migration response to differences in current wages while controlling for differences in future labor wealth by including expected future migration. Such an approach allows the coefficient on current wages to be interpreted as the migration response to the implied difference in labor wealth; in other words, it is straightforward to

\footnotetext{
${ }^{14}$ The speeds of convergence in this and the next paragraph are based on a narrow capital share, $\alpha=0.30$, a unitary elasticity of intertemporal substitution (which matches the implicit assumption in the local growth model), and the remaining parameter values enumerated in Figure 1.

${ }^{15}$ Rappaport (2000) shows that introducing an aggregate average installation cost which is convex increasing with respect to gross investment allows the open-economy version of the Ramsey model to be calibrated to achieve both a steady-state shadow value of capital very close to one as well as a slow speed of convergence even at income levels substantially below the steady state.
} 
calculate the ratio of local to row labor wealth implied by a given ratio of local to row wages which lasts for one period only. Depending on the assumed real interest rate, Gallin's baseline estimate implies that it takes from a 0.3 percent to a 1.0 percent labor wealth premium to induce a 1 percent rate of net migration. Actual labor mobility may be even higher as Gallin does not control for variations in quality of life. ${ }^{16}$

Consistent with Gallin's estimates, I assume a "base" level of labor mobility such that a 1 percent real wealth differential is sufficient to induce a 1 percent annual rate of net migration $(\omega=1.01)$. In the subsection which follows, I explore the effects of varying $\omega$ to capture levels of labor mobility both much higher and much lower than the base calibration. The arguably "high" labor mobility of the base calibration (e.g., relative to the Barro and Sala-i-Martin estimates) along with the inclusion of an alternative calibration with even much higher labor mobility underlies the claim in the previous section that the friction proportional to the net population flow rate need only be "very small".

\subsection{Alternative Calibrations: The Effect of Factor Mobility on Income Convergence}

Finally, then, to directly address the question, how does factor mobility affect income convergence? Figure 2 shows the time paths of population, gross capital stock, wages, and land prices following a negative capital shock under alternative "high" and "low" labor mobility calibrations. In the high labor mobility regime just a $1 / 8$ percent difference in real wealth will induce a 1 percent annual rate of net migration $(\omega=1.00125)$; under the low labor-mobility regime an 8 percent difference is needed to do the same $(\omega=1.08)$. In terms of the labor friction parameter, $b_{L}$, the high regime has 64 times the mobility of the low regime. All other parameters are the same as in Figure 1.

Unsurprisingly, the rate of population outflow immediately following the capital shock is much greater under the high labor mobility regime than under the low one; the respective initial rates of outmigration are 15.9 percent versus just 0.6 percent (Figure 2 Panel A). With high labor mobility, population eventually drops to a minimum 68 percent of its initial

\footnotetext{
${ }^{16}$ Including expected future migration should be able to control for future differences in quality of life. But in the present case, Gallin proxies for expected migration using actual future migration instrumented by predicted employment growth based on industry shares. To the extent that such an instrument fails to capture quality-of-life attributes, expected migration will be that arising from productivity-based wealth differences only.
} 
level 7 years after the shock. With low labor mobility, the population outflow continues for a longer period but is much shallower; a minimum population 97 percent of its initial level is reached 16 years after the shock. With high labor mobility, the return population flow is also much more rapid and by year 46, population under the high regime comes to exceed that under the low regime. But greater asset deccumulation implies that in the final steady state, the low labor mobility regime will have the higher population. (The second intersection of the population loci is not shown as it takes place more than 100 years after the initial shock.)

Labor outflows drive down the marginal revenue product of capital with the result that gross capital formation is slower under high than under low labor mobility; immediately following the negative capital shock, the respective annual rates of gross capital formation are 20.4 percent versus 25.9 percent (Figure 2 Panel B). 10 years after the negative capital shock, extensive capital stock normalized for the level of technology is 10 percentage points lower with high labor mobility than with low labor mobility (i.e., the vertical gap between the loci); after 20 years the difference is 12 percentage points. From a post-shock level 18 percent of its pre-shock level, it takes 15 years for extensive capital to reach 80 percent of its pre-shock level with high labor mobility but just 10 years to do so with low labor mobility.

The inverse correlation of labor and capital flows following capital shocks implies a substitutability between labor and capital mobility. For a given level of capital mobility, increases in labor mobility and hence population flows are associated with decreases in gross capital formation (Table 1 column 4 moving down across rows within a given panel); for a given level of labor mobility, increases in capital mobility and hence gross capital formation are associated with decreases in population flows (Table 1 column 3 moving down across panels for a given row).

In terms of the speed at which income converges back to its long run steady state, the higher initial outflow of population with high labor mobility contributes to a positive effect of labor mobility on income convergence; the higher growth rate of extensive capital with low labor mobility contributes to a negative effect of labor mobility on income convergence. Figure 2 Panel C shows the combined effect. Immediately following the capital shock, wages grow faster with high labor mobility than with low; the initial growth rates are 0.109 versus 0.080, respectively. After 10 years, wages have returned to 89.9 percent of their pre-shock level with high labor mobility versus 86.5 percent of their pre-shock level with low labor 
mobility (the vertical gap between loci). For wages to reach 90 percent of their pre-shock level takes 10.1 years with high labor mobility versus 13.0 years with low labor mobility (the horizontal gap between loci).

Table 1 Panel B summarizes speed of convergence measures for alternative levels of labor mobility under the base calibration capital share of production, $\alpha=0.30$, and shadow value of capital, $q_{K}^{*}=1.56$. The remaining panels show the effect of varying labor mobility on the speed of income convergence under alternative calibrations of the shadow value of capital and capital share of production. Note that within a panel, each row represents a halving of the labor mobility friction relative to the row above; the top row shows the speed of convergence measured in a corresponding neoclassical, open-economy model in which population is assumed fixed.

What is surprising is the extent to which the time paths of wages under high versus low mobility remain quite close to each other. So for the base calibration in Table 1 Panel $\mathrm{B}$, moving from the second row, where a 32 percentage point wealth difference induces a 1 percent rate of net migration, to the last row, where just a 1/16 percentage point wealth difference is needed to do the same, the relative wage 10 years after the negative capital shock increases from 0.863 to 0.903 ; the time until wages reattain 90 percent of their steady-state level decreases from 13.2 years to 9.6 years. Such changes would seem qualitatively small when compared with the more than thousand-fold increase in the labor mobility friction. The speed of income convergence is especially insensitive to increases in labor mobility from low levels. Moving down from the top row, in which labor mobility is completely absent, to the low labor mobility calibration in the fourth row is associated with virtually no change in the various speed of convergence measures, the one exception being the asymptotic speed of convergence which again emphasizes that it is a misleading metric.

Measured at a point closer to the steady state, the speed of income convergence actually slows with increasing labor mobility. For instance, under the base capital mobility and capital share calibration, 20 years after the capital shock relative wages are 0.955 with the base labor mobility but only 0.953 with high labor mobility. Similarly, the time it takes for wages to reattain 99 percent of their steady-state level continually increases from 37.3 years under the low labor mobility calibration to 40.7 years under the base calibration to 47.4 years under the high labor mobility calibration (Table 1 Panel B, columns 12 and 16).

Figure 3 Panel A plots the relative wage 10 years after the negative shock against 
increasing levels of labor mobility. The horizontal axis is denominated such that each horizontal unit corresponds to a halving of the labor mobility friction. The three loci correspond to "low", "base", and "high" levels of capital mobility with steady-state shadow values of capital equal to $3.24,1.56$, and 1.14 respectively (corresponding to Table 1, Panels A through $\mathrm{C}$ ). That the loci are positively sloped captures that the speed of convergence as measured by relative wages 10 years after the shock is indeed increasing with labor mobility. That the loci are relatively flat captures that the effect of labor mobility on income convergence is relatively small. Measured at points closer to the steady state (for instance, $\mathrm{t}=40$ ), the loci are negatively sloped (i.e., the speed of convergence is inversely correlated with labor mobility).

In contrast to labor mobility, the degree of capital mobility exerts a powerful influence on the speed of income convergence. Figure 3 Panel B plots the relative wage 10 years after the negative capital shock against increasing levels of capital mobility. The horizontal axis is scaled such that each horizontal unit corresponds to a halving of the capital installation cost. Except at very high levels of capital mobility, the wage level is steeply increasing as the capital installation cost decreases. For the base level of labor mobility $(\omega=1.01)$, a halving of the capital installation cost such that the steady-state shadow value of capital decreases from $q_{K}^{*}=1.28$ to $q_{K}^{*}=1.14$ is associated with an increase in the 10-year relative wage from 0.911 to 0.946 . And regardless of the time at which they are measured, relative wages are always increasing with the degree of capital mobility.

An alternative illustration of the relationship between income convergence and factor mobility is captured by the vertical gaps between loci in Figure 3, Panels A and B. In Panel A, each locus represents a quadrupling of the capital friction relative to the locus above it; the vertical gaps represent the difference in relative wages 10 years after the negative capital shock for various levels of labor mobility. In Panel B, each locus represents an eight-fold increase of the labor friction relative to the locus above it; here the vertical gaps represent the difference in relative wages ten years after the shock for various levels of capital mobility. That the vertical gaps are much greater in Panel A than in Panel B (even though the difference in relative frictions between adjacent loci is twice as geat in Panel B) captures that the speed of income convergence is much more sensitive to variations in capital mobility than it is to variations in labor mobility.

In general, labor mobility proves a weak substitute for capital mobility but capital 
mobility proves a powerful substitute for labor mobility. The horizontal gaps between loci in Figure 3 Panel B capture the increase in capital mobility needed to offset the eight-fold decrease in labor mobility between adjacent loci. To offset a decrease in labor mobility from $\omega=1.01$ to $\omega=1.08$ requires only a very small increase in capital mobility (i.e., to maintain the same 10-year relative wage). For the four-fold decrease in capital mobility between adjacent loci in Panel A, there is no increase in labor mobility sufficient to maintain the same 10-year relative wage.

Figure 3, Panels C and D parallel Panels A and B except that they measure the speed of convergence by the time it takes for wages to reattain 90 percent of their steady-state level. The speed of convergence so measured again proves relatively insensitive to the degree of labor mobility but highly sensitive to the degree of capital mobility. Measured to relative wages closer to the steady state, the loci in Panel $\mathrm{C}$ are positively sloped (e.g., Table 1 Column 16).

Within the current framework, the insensitivity of the speed of income convergence to the degree of labor mobility is an extremely robust qualitative result. Even under the parameter calibration effecting the highest sensitivity (low capital mobility with high labor mobility), the increase in convergence speed brought about by an increase in labor mobility is minimal. Under the narrow capital share, low capital mobility calibration, tripling the labor mobility from its base level results in less than a 4 percentage point difference in wages 10 years after the (forty-percentage-point) income shock and virtually no difference in wages 20 years after the shock. The same increase in labor mobility shortens the time for wages to reattain 90 percent of their steady-state level by only 2.3 years (from 17.9 to 15.6) and actually increases the time it takes for wages to reattain 95 percent of their steady-state level (Table 1, Panel A; Figure 3, Panel A, bottom locus; Figure 3, Panel C, top locus). As the low capital mobility calibration corresponds to a shadow value of capital far larger than empirical estimates, such numbers suggest a modest upper bound on the real world potential contribution of labor mobility to convergence speed. ${ }^{17} 18$

\footnotetext{
${ }^{17}$ Another reason for choosing a relatively low capital friction is the possibility of capital reallocation from capital-intensive to labor-intensive tradable good production in a Heckscher-Ohlin framework. Following a negative capital shock, such reallocation contributes to factor price equalization and so is analogous to a faster capital inflow.

${ }^{18}$ The combination of a broad capital share with a high capital friction does effect a larger contribution of labor mobility to the speed of income convergence (Table 1, Panel D). However, as one of the main
} 
From a welfare perspective, the numerical results show that local residents' utility immediately following a negative capital shock is strictly increasing in the level of labor mobility. Thus the higher relative wages during the early part of the transition path dominate lower relative wages during the latter part of the transition. In addition, the greater outflow of population with high labor mobility causes a greater decrease in the price of local housing services thereby increasing real (as opposed to output denominated) wages. Of course to the extent that local housing is owned by local residents (the model assumes absentee landlords), the lower housing service prices associated with high labor mobility would contribute to losses in local asset wealth. Whether such an "asset wealth" effect of labor mobility is sufficient to cause welfare to become decreasing in the level of labor mobility awaits the extension of local growth theory to explicitly incorporate local housing ownership.

\section{Conclusions}

Extending the neoclassical growth model to allow for labor mobility shows that the disincentive effect of population flows on gross capital formation roughly offsets the direct effect of population flows on income convergence. The resulting insensitivity of the speed of income convergence to labor mobility is extremely robust to alternative assumptions and parameterizations. And so to the extent that the world economy is becoming more integrated, it seems unlikely that increased labor mobility will increase the rate at which poor countries catch up to rich ones. More relevant may be the concern that in a world slightly more complicated than modeled above, increased labor mobility may actually slow income convergence due to emigration from poor economies of indivduals with high levels of human capital.

Rather than labor mobility, capital mobility serves as the key determinant of the speed of income convergence. The result suggests that policies seeking to develop the poorer regions of large economies focus on lowering the frictions to capital formation.

At a more basic level, the model's varying convergence speed and history dependence illustrate that the neoclassical framework can capture a rich set of phenomenon heretofore motivations for using a broad capital share calibration is to avoid using a high capital friction calibration, this latter example would not seem relevant. With the combination of a broad capital share and a low capital friction, the insensitivity result holds (Table 1, Panel F). 
largely the preserve of models underpinned by stronger assumptions. Neoclassical growth theory still has much to teach us.

\section{Appendices}

\section{A Local Growth Equations of Motion and Steady-State Levels}

The seven system equations of motion are given by,

$$
\begin{aligned}
& \frac{\mathrm{d}}{\mathrm{d} t} L_{i}=\frac{d U_{\text {wealth }, i}+d U_{\text {price }, i}}{b_{L}} L_{i} \\
& \frac{\mathrm{d}}{\mathrm{d} t} \hat{k}_{i}=\left(\frac{q_{k, i}-1}{b_{K}}-\delta-x-\frac{d U_{\text {wealth }, i}+d U_{\text {price }, i}}{b_{L}}\right) \hat{k}_{i} \\
& \frac{\mathrm{d}}{\mathrm{d} t} \widehat{\operatorname{assets}}_{i}=(1-\alpha) A \hat{k}_{i}^{a}+\rho \widehat{\operatorname{asset}}_{i}-\rho\left(\text { labor_wealth }_{\text {row }}+\widehat{\operatorname{assets}}_{i}\right) \mathrm{e}^{\rho d U_{\text {wealth }, i}} \\
& \frac{\mathrm{d}}{\mathrm{d} t} q_{K, i}=(\delta+\rho+x) q_{K, i}-\alpha A \hat{k}_{i}^{-(1-\alpha)}-\frac{\left(q_{K, i}-1\right)^{2}}{2 b_{K}} \\
& \frac{\mathrm{d}}{\mathrm{d} t} d U_{\text {wealth }, i}=\mathrm{e}^{\rho d U_{\text {wealth }, i}}-\frac{(1-\alpha) A \hat{k}_{i}^{a}+\rho \widehat{\text { assets }}_{i}}{\rho\left(\text { labor_wealth }_{\text {row }}+\widehat{\operatorname{assets}}_{i}\right)} \\
& \frac{\mathrm{d}}{\mathrm{d} t} d U_{\text {price }, i}=\zeta \log \left(\frac{\zeta \rho\left(\text { labor_wealth }_{\text {row }}+\widehat{\text { assets }}_{i}\right) L_{i}}{\hat{p}_{\text {row }} N_{i}}\right) \\
& \frac{\mathrm{d}}{\mathrm{d} t} \widehat{\text { value }}_{i}=\rho{\widehat{\text { value }_{i}}}_{i}-\frac{\zeta \rho\left(\text { labor_wealth }_{\text {row }}+\widehat{\operatorname{asset}}_{i}\right) L_{i} \mathrm{e}^{\rho d U_{\text {wealth }, i}}}{N_{i}}
\end{aligned}
$$

Setting each of the system equations equal to zero implies steady-state levels,

$$
L_{i}^{*}=\left(\frac{(1-\alpha) A^{\frac{1}{1-\alpha}}\left(\frac{2 \alpha}{\widetilde{b}_{K}}\right)^{\frac{\alpha}{1-\alpha}}+\rho \cdot \widehat{\operatorname{assets}}_{\text {row }}^{*}}{(1-\alpha) A^{\frac{1}{1-\alpha}}\left(\frac{2 \alpha}{\widehat{b}_{K}}\right)^{\frac{\alpha}{1-\alpha}}+\rho \cdot \widehat{\operatorname{assets}}_{i}^{*}}\right)\left(\frac{N_{i}}{n_{\text {row }}}\right)
$$

where,

$$
\begin{gathered}
\widetilde{b}_{K} \equiv 2(x+\rho+\delta)+\left(x^{2}+\delta^{2}+2 x \delta+2 x \rho+2 \delta \rho\right) \cdot b_{K} \\
\widehat{k}_{i}^{*}=A^{\frac{1}{1-\alpha}}\left(\frac{2 \alpha}{\widetilde{b}_{K}}\right)^{\frac{1}{1-\alpha}}
\end{gathered}
$$




$$
\begin{aligned}
& \widehat{\operatorname{assets}}_{i}^{*}=\widehat{\operatorname{asset}}_{i}^{*} \\
& q_{K, i}^{*}=1+(x+\delta) b_{K} \\
& d U_{\text {wealth }, i}^{*}=0 \\
& d U_{\text {price }, i}^{*}=0 \\
& \widehat{\operatorname{value}}_{i}^{*}=\left((1-\alpha) A^{\frac{1}{1-\alpha}}\left(\frac{2 \alpha}{\widetilde{b}_{K}}\right)^{\frac{\alpha}{1-\alpha}}+\rho \cdot \widehat{\operatorname{assets}}_{\text {row }}^{*}\right) \cdot\left(\frac{1}{\rho n_{\text {row }}}\right) \cdot
\end{aligned}
$$

\section{B Convergence with More than One State Variable: Some Algebra}

Two key characteristics of the dynamic model are, first, that its steady-state is not uniquely determined but rather depends on history; and second, that the speed of convergence - the rate at which income and population approach their steady-state levels normalized by their distances from their respective steady-state levels - varies greatly, even in a neighborhood quite close to the steadystate. It turns out that both properties, history dependence and a varying speed of convergence, are generic with multiple state (i.e., "non-jumping") variables. The "proof" lies mainly in pointing out the necessity of an $\mathrm{N}$-dimensional surface to span an $\mathrm{N}$-dimensional space. That is, to assure that some steady state can be reached from any feasible starting-value combination of state variables, the dimensionality of possibly multiple steady states plus the dimensionality of the transition surface to each of these must sum to the number of state variables.

A steady state with dimensionality one or more is equivalent to history dependence. Such history dependence is more common than is often believed. Barro (1979) shows there is no one optimal level of government debt; rather, a country's optimal debt depends on its specific history of shocks (i.e., wars, famines, baby booms, natural resource finds, etc.). In two sector endogenous growth models (Mulligan and Sala-i-Martin, 1993; Caballe and Santos, 1993), the ratio but not the level of human to physical capital is determinate (the level however is less interesting within an endogenous growth framework).

The linearization of a transition path with two or more dimensions will always show an increasing speed of convergence: near the steady-state the negative eigenvalue lowest in absolute value will dominate; as one moves away from the steady-state, the negative eigenvalue highest in absolute value will dominate. The algebra showing this follows immediately below. That the asymptotic speed of convergence is given by the negative eigenvalue lowest in absolute value is also pointed out 
by Eichner and Turnovsky (1999). The actual transition path (rather than its linearized approximation) may show an increasing, constant, or decreasing speed of convergence. A constant speed of convergence, however, would be a razor thin result.

Some definitions:

$$
\begin{aligned}
& \left.\mathbf{b} \equiv\left[\begin{array}{c}
b_{1} \\
b_{2} \\
\vdots \\
\vdots \\
b_{n}
\end{array}\right] \quad \mathbf{z} \equiv\left[\begin{array}{c}
z_{1} \\
z_{2} \\
\vdots \\
\vdots \\
z_{n}
\end{array}\right] \quad \mathbf{l} \equiv\left[\begin{array}{c}
1 \\
1 \\
\vdots \\
\vdots \\
1
\end{array}\right]\right) \text { n times } \\
& \mathbf{b} \odot \mathbf{z} \equiv\left[\begin{array}{c}
b_{1} z_{1} \\
b_{2} z_{2} \\
\vdots \\
\vdots \\
b_{n} z_{n}
\end{array}\right] \quad \mathbf{b} \oslash \mathbf{z} \equiv\left[\begin{array}{c}
b_{1} / z_{1} \\
b_{2} / z_{2} \\
\vdots \\
\vdots \\
b_{n} / z_{n}
\end{array}\right] \quad \log \mathbf{z} \equiv\left[\begin{array}{c}
\log z_{1} \\
\log z_{2} \\
\vdots \\
\vdots \\
\log z_{n}
\end{array}\right] \\
& \mathbf{A}(\mathbf{z}) \equiv\left[\begin{array}{ccccc}
A_{11}(\mathbf{z}) & A_{12}(\mathbf{z}) & \cdots & \cdots & A_{1 n}(\mathbf{z}) \\
A_{21}(\mathbf{z}) & \ddots & & & \vdots \\
\vdots & & \ddots & & \vdots \\
\vdots & & & \ddots & \vdots \\
A_{n 1}(\mathbf{z}) & \cdots & \cdots & \cdots & A_{n n}(\mathbf{z})
\end{array}\right] \\
& \frac{\partial \mathbf{A}(\mathbf{z})}{\partial \mathbf{z}} \equiv\left[\begin{array}{ccccc}
\frac{\partial A_{11}(\mathbf{z})}{\partial z_{1}} & \frac{\partial A_{12}(\mathbf{z})}{\partial z_{2}} & \cdots & \ldots & \frac{\partial A_{1 n}(\mathbf{z})}{\partial z_{n}} \\
\frac{\partial A_{21}(\mathbf{z})}{\partial z_{1}} & \ddots & & & \vdots \\
\vdots & & \ddots & & \vdots \\
\vdots & & & \ddots & \vdots \\
\frac{\partial A_{n 1}(\mathbf{z})}{\partial z_{1}} & \cdots & \ldots & \ldots & \frac{\partial A_{n n}(\mathbf{z})}{\partial z_{n}}
\end{array}\right]
\end{aligned}
$$

Suppose a system of differential equations defined in terms of the logarithms of the vector of variables, $\mathbf{z}$ :

$$
\frac{\mathrm{d}}{\mathrm{d} t} \log \mathbf{z}=\mathbf{A}(\log \mathbf{z})
$$

Take a Taylor expansion around the system's steady-state:

$$
\begin{aligned}
\frac{\mathrm{d}}{\mathrm{d} t} \log \mathbf{z} & \approx \mathbf{A}\left(\log \mathbf{z}^{*}\right)+\left.\frac{\partial \mathbf{A}(\log \mathbf{z})}{\partial \log \mathbf{z}}\right|_{\log \mathbf{z}=\log \mathbf{z}^{*}} \cdot\left(\log \mathbf{z}-\log \mathbf{z}^{*}\right) \\
& =\mathbf{J} \log \left(\mathbf{z} \oslash \mathbf{z}^{*}\right)
\end{aligned}
$$




$$
\left.\mathbf{J} \equiv \frac{\partial \mathbf{A}(\log \mathbf{z})}{\partial \log \mathbf{z}}\right|_{\log \mathbf{z}=\log \mathbf{z}^{*}}
$$

Let $\left|\lambda_{f}\right|>\left|\lambda_{s}\right|$ represent two negative eignevalues of $\mathbf{J}$ with corresponding eigenvectors $\mathbf{v}_{f}$ and $\mathbf{v}_{s}$, and arbitrary weighting scalars, $a_{f}$ and $a_{s}$ (" $f$ " is meant to connote "fast" and " $s$ ", "slow").

$$
\mathbf{J}\left(a_{f} \mathbf{v}_{f}+a_{s} \mathbf{v}_{s}\right)=-\left(\lambda_{f} a_{f} \mathbf{v}_{f}+\lambda_{s} a_{s} \mathbf{v}_{s}\right)
$$

Then the solution to (B.2b) can be written as,

$$
\log \left(\mathbf{z} \oslash \mathbf{z}^{*}\right) \approx a_{f} \mathbf{v}_{f} \mathrm{e}^{-\lambda_{f} t}+a_{s} \mathbf{v}_{s} \mathrm{e}^{-\lambda_{s} t}
$$

Take the derivative of (B.4) with respect to $t$,

$$
\frac{\mathrm{d}}{\mathrm{d} t} \log \left(\mathbf{z} \oslash \mathbf{z}^{*}\right) \approx-\left(\lambda_{f} a_{f} \mathbf{v}_{f} \mathrm{e}^{-\lambda_{f} t}+\lambda_{s} a_{s} \mathbf{v}_{s} \mathrm{e}^{-\lambda_{s} t}\right)
$$

The canonical underlying structural form for growth regressions is,

$$
\frac{\mathrm{d}}{\mathrm{d} t} \log z=\frac{\mathrm{d}}{\mathrm{d} t}\left(\log z-\log z^{*}\right)=-\lambda \cdot\left(\log z-\log z^{*}\right)
$$

For the vector analog to this we want,

$$
\boldsymbol{\lambda} \text { s.t. } \frac{\mathrm{d}}{\mathrm{d} t} \log \left(\mathbf{z} \oslash \mathbf{z}^{*}\right)=-\boldsymbol{\lambda} \odot \log \left(\mathbf{z} \oslash \mathbf{z}^{*}\right)
$$

Substituting using (B.4) and (B.5) gives,

$$
\boldsymbol{\lambda} \text { s.t. }\left(\lambda_{f} a_{f} \mathbf{v}_{f} \mathrm{e}^{-\lambda_{f} t}+\lambda_{s} a_{s} \mathbf{v}_{s} \mathrm{e}^{-\lambda_{s} t}\right) \approx \boldsymbol{\lambda} \odot\left(a_{f} \mathbf{v}_{f} \mathrm{e}^{-\lambda_{f} t}+a_{s} \mathbf{v}_{s} \mathrm{e}^{-\lambda_{s} t}\right)
$$

It is immediately evident that unless either $a_{f}$ or $a_{s}$ equal zero, $\boldsymbol{\lambda}$ will differ in its elements and vary with time. I now formally define $\boldsymbol{\lambda}(t)$ as,

$$
\boldsymbol{\lambda}(t) \equiv-\frac{\mathrm{d}}{\mathrm{d} t} \log \left(\mathbf{z} \oslash \mathbf{z}^{*}\right) \oslash \log \left(\mathbf{z} \oslash \mathbf{z}^{*}\right)
$$

The log linearization therefore approximates the speed of convergence as,

$$
\boldsymbol{\lambda}(t) \approx\left(\lambda_{f} a_{f} \mathbf{v}_{f} \mathrm{e}^{-\lambda_{f} t}+\lambda_{s} a_{s} \mathbf{v}_{s} \mathrm{e}^{-\lambda_{s} t}\right) \oslash\left(a_{f} \mathbf{v}_{f} \mathrm{e}^{-\lambda_{f} t}+a_{s} \mathbf{v}_{s} \mathrm{e}^{-\lambda_{s} t}\right)
$$

Normalize the eigenvectors so that the first element of each equals one. Then the speed of convergence corresponding to this first element is given by,

$$
\lambda_{1}(t) \approx \frac{\lambda_{f} a_{f} \mathrm{e}^{-\lambda_{f} t}+\lambda_{s} a_{s} \mathrm{e}^{-\lambda_{s} t}}{a_{f} \mathrm{e}^{-\lambda_{f} t}+a_{s} \mathrm{e}^{-\lambda_{s} t}}
$$

So except in the special case when $a_{f}$ or $a_{s}$ equal zero, the linearization implies the speed of convergence for this representative first element will go from $a_{f}$ to $a_{s}$ as time goes from negative to positive infinity. If $a_{f}$ and $a_{s}$ are oppositely signed, it will also asymptote to positive and negative infinity at some intermediate time. 


\section{Bibliography}

Abel, Andrew B. (1982). "Dynamic Effects of Permanent and Temporary Tax Policies in a $q$ Model of Investment." Journal of Monetary Economics 9, pp. 353-373.

Ades, Alberto F. and Edward L. Glaeser (1994). "Evidence on Growth, Increasing Returns, and the Extent of the Market." NBER Working Paper No. 4714 (April).

Barnett, Steven A. and Plutarchos Sakellaris (1998). "Nonlinear Response of Firm Investment to Q: Testing the Model of Convex and Nonconvex Adjustment Costs." Journal of Monetary Economics 42, 2 (October), pp. 261- 288.

Barro, Robert J. (1979). "On the Determination of Public Debt." Journal of Political Economy, 87, (Oct.), pp. 940-971.

Barro, Robert J. and Xavier Sala-i-Martin (1992). "Convergence." Journal of Political Economy 100, 2 (April), pp. 223-251.

Barro, Robert J. and Xavier Sala-i-Martin, (1991). "Convergence across States and Regions." Brookings Papers on Economic Activity, 1:1991, pp. 107-182.

Barro, Robert J. and Xavier Sala-i-Martin (1995). Economic Growth. New York: McGraw Hill.

Blanchard, Olivier J. and Lawrence F. Katz (1992). "Regional Evolutions." Brookings Papers on Economic Activity 1:1992.

Blanchard, Olivier, Changyong Rhee, and Lawrence Summers (1993). "The Stock Market, Profit, and Investment." Quarterly Journal of Economics 108, 1 (Feb.), pp. 115-136.

Braun, Juan (1993). Essays on Economic Growth and Migration. Ph.D. dissertation, Harvard University.

Caballé, Jordi and Manuel S. Santos (1993). "On Endogenous Growth with Physical and Human Capital." Journal of Political Economy 101, 6 (Dec.), pp. 1042-1067.

Caselli, Francesco, Gerardo Esquivel, and Fernando Lefort (1996). "Reopening the Convergence Debate: A New Look at Cross-Country Growth Empirics." Journal of Economic Growth 1, 3 (September), pp. 363-389.

Cass, David (1965). "Optimum Growth in an Aggregative Model of Capital Accumulation." Review of Economic Studies 32 (July), pp. 233-240.

Durlauf, Steven N. and Danny T. Quah (1998). "The New Empirics of Economic Growth." Center for Economic Performance Discussion Paper 384, (January).

Eicher, Theo S. and Stephen J. Turnovsky (1999). "Convergence in a Two-Sector Nonscale Growth Model." Journal of Economic Growth 4, 4 (Dec.), pp. 413-428.

Evans, Paul (1997). "How Fast Do Economies Converge?" Review of Economics and Statistics 79, 2 (May), pp. 219-225.

Evans, Paul and Georgios Karras (1996). "Convergence Revisited." Journal of Monetary Economics 37, 2 (April), pp. 249-265. 
Gallin, Joshua Hojvat (1999). "Net Migration and State Labor Market Dynamics." Federal Reserve Board of Governors, Finance and Economics Discussion Series Paper 1999-16.

Gyourko, Joseph and Joseph Tracy (1989). "The Importance of Local Fiscal Conditions in Analyzing Local Labor Markets." Journal of Political Economy 97, 5 (Oct.), pp. 1208-1231.

Gyourko, Joseph and Joseph Tracy (1991). "The Structure of Local Public Finance and the Quality of Life." Journal of Political Economy 99, 4 (Aug.), pp. 774-806.

Hatton, Timothy J. and Jeffrey G. Williamson (1998). The Age of Mass Migration. New York: Oxford University Press.

Hayashi, Fumio (1982). "Tobin's Marginal $q$ and Average q: A Neoclassical Interpretation." Econometrica 50, 1 (Jan.), pp. 213-224.

Islam, Nazrul (1995). "Growth Empirics: a Panel Data Approach." Quarterly Journal of Economics 110, 4 (November), pp. 1127-1170.

King, Robert G. and Sergio T. Rebelo (1993). "Transitional Dynamics and Economic Growth in the Neoclassical Model." American Economic Review 83, 4 (September), pp. 908-931.

Koopmans, Tjalling C. (1965). "On the Concept of Optimal Economic Growth." The Econometric Approach to Development Planning. Amsterdam: North Holland.

Krugman, Paul (1991). Geography and Trade. Cambridge, MA: MIT Press.

Mueser, Peter R. and Philip E. Graves (1995). "Examining the Role of Economic Opportunity and Amenities in Explaining Population Redistribution." Journal of Urban Economics 37, 2 (March), pp. $176-200$.

Mulligan, Casey B. and Xavier Sala-i-Martin (1993). "Transitional Dynamics in Two-Sector Models of Endogenous Growth." Quarterly Journal of Economics 108, 3 (Aug) pp. 739-773.

Ramsey, Frank (1928). "A Mathematical Theory of Saving." Economic Journal 38 (Dec.), pp. $543-559$.

Rappaport, Jordan (1999a). "Local Growth Empirics." Working Paper No. 23, Center for International Development, Harvard University, (July).

Rappaport, Jordan (1999b). "Why are Population Flows So Persistent?" Federal Reserve Bank of Kansas City RWP 99-13, (November).

Rappaport, Jordan (2000). "How Does Openness to Capital Flows Affect Growth." Mimeo, Federal Reserve Bank of Kansas City, (June).

Roback, Jennifer (1982). "Wages, Rents, and the Quality of Life." Journal of Political Economy 90, 6 (Dec.), pp. 1257-1278.

Rosen, Sherwin (1979). "Wage-Based Indexes of Urban Quality of Life." In Miezkowski and Straszheim, Eds., Current Issues in Urban Economics. Baltimore: Johns Hopkins University Press.

Tiebout, Charles M. (1956). "A Pure Theory of Local Expenditures." Journal of Political Economy 64, 5 (Oct.), pp. 416-424. 
Table 1: Factor Mobility and Income Convergence

Numerical results for a negative capital shock that drops wages to $60 \%$ of their steady-state level. For narrow capital share, $(\alpha=0.30)$, per capita capital stock drops to $18.2 \%$ of its steady-state level.

A. Low Capital Mobility $\left(\mathrm{q}_{\mathrm{K}}{ }^{*}=3.24\right)$, Narrow Capital Share $(\alpha=0.30)$

\begin{tabular}{|c|c|c|c|c|c|c|c|c|c|c|c|c|c|c|c|}
\hline \multirow{3}{*}{$\begin{array}{c}(1) \\
\text { labor } \\
\text { mobility }\end{array}$} & \multirow{3}{*}{$\begin{array}{c}(2) \\
\text { labor } \\
\text { friction } \\
(\omega)\end{array}$} & (3) & (4) & (5) & (6) & (7) & (8) & (9) & (10) & (11) & (12) & (13) & (14) & (15) & (16) \\
\hline & & \multicolumn{3}{|c|}{$\begin{array}{l}\text { Initial Growth Rates } \\
\quad(\text { at } t=0)\end{array}$} & \multicolumn{2}{|c|}{$\begin{array}{l}\text { Population } \\
\text { Minimum }\end{array}$} & $\begin{array}{l}\text { Cnvrg } \\
\text { Speed }\end{array}$ & \multicolumn{4}{|c|}{$\begin{array}{l}\text { Relative Wage at Time } \\
\text { (in years) }\end{array}$} & \multicolumn{4}{|c|}{$\begin{array}{l}\text { Time to Reach } \\
\text { Relative Wage }\end{array}$} \\
\hline & & pop & capital & wages & level & time & $t=\infty$ & $t=1$ & $\mathrm{t}=5$ & $t=10$ & $t=20$ & $80 \%$ & $90 \%$ & $95 \%$ & $99 \%$ \\
\hline \multirow[t]{3}{*}{ zero } & $\infty$ & & 0.167 & 0.050 & & & 0.059 & 0.629 & 0.721 & 0.801 & 0.895 & 9.9 & 20.8 & 32.1 & 59.1 \\
\hline & 1.32 & -0.002 & 0.165 & 0.050 & 0.98 & 25.3 & 0.005 & 0.629 & 0.722 & 0.802 & 0.896 & 9.8 & 20.6 & 31.8 & 59.2 \\
\hline & 1.16 & -0.004 & 0.165 & 0.051 & 0.96 & 24.6 & 0.009 & 0.629 & 0.723 & 0.803 & 0.897 & 9.8 & 20.4 & 31.5 & 59.4 \\
\hline \multirow[t]{3}{*}{ low } & 1.08 & -0.008 & 0.160 & 0.050 & 0.94 & 22.7 & 0.013 & 0.629 & 0.724 & 0.805 & 0.899 & 9.6 & 20.1 & 31.1 & 60.3 \\
\hline & 1.04 & -0.014 & 0.156 & 0.051 & 0.90 & 20.6 & 0.019 & 0.630 & 0.726 & 0.808 & 0.903 & 9.4 & 19.6 & 30.6 & 62.9 \\
\hline & 1.02 & -0.025 & 0.151 & 0.053 & 0.85 & 17.6 & 0.025 & 0.631 & 0.730 & 0.814 & 0.908 & 9.0 & 18.8 & 29.9 & 68.1 \\
\hline \multirow[t]{3}{*}{ base } & 1.01 & -0.043 & 0.145 & 0.057 & 0.79 & 15.0 & 0.029 & 0.633 & 0.737 & 0.823 & 0.913 & 8.4 & 17.9 & 29.6 & 74.0 \\
\hline & 1.005 & -0.071 & 0.137 & 0.062 & 0.73 & 12.3 & 0.032 & 0.636 & 0.749 & 0.836 & 0.917 & 7.6 & 16.9 & 30.1 & 76.2 \\
\hline & 1.0025 & -0.111 & 0.128 & 0.072 & 0.67 & 10.0 & 0.033 & 0.642 & 0.765 & 0.849 & 0.919 & 6.7 & 16.0 & 31.3 & 76.3 \\
\hline \multirow[t]{2}{*}{ high } & 1.00125 & -0.174 & 0.122 & 0.089 & 0.62 & 8.2 & 0.034 & 0.650 & 0.784 & 0.861 & 0.918 & 5.7 & 15.6 & 32.6 & 76.0 \\
\hline & 1.000625 & -0.260 & 0.115 & 0.113 & 0.57 & 6.5 & 0.035 & 0.662 & 0.804 & 0.867 & 0.916 & 4.8 & 15.7 & 33.3 & 75.5 \\
\hline
\end{tabular}

B. Base Capital Mobility $\left(q_{K}{ }^{*}=1.56\right)$, Narrow Capital Share $(\alpha=0.30)$

\begin{tabular}{|c|c|c|c|c|c|c|c|c|c|c|c|c|c|c|c|}
\hline \multirow[t]{2}{*}{$\begin{array}{c}(1) \\
\text { labor } \\
\text { mobility }\end{array}$} & \multirow{2}{*}{$\begin{array}{c}(2) \\
\text { labor } \\
\text { friction } \\
(\omega)\end{array}$} & \multicolumn{3}{|c|}{$\begin{array}{l}\text { Initial Growth Rates } \\
\qquad(\text { at } \mathrm{t}=0)\end{array}$} & \multicolumn{2}{|c|}{$\begin{array}{l}\text { Population } \\
\text { Minimum }\end{array}$} & \multirow{2}{*}{$\begin{array}{c}(8) \\
\text { Cnvrg } \\
\text { Speed } \\
t=\infty\end{array}$} & \multicolumn{4}{|c|}{$\begin{array}{c}\text { Relative Wage at Time } \\
\text { (in years) }\end{array}$} & \multicolumn{4}{|c|}{$\begin{array}{l}\text { Time to Reach } \\
\text { Relative Wage }\end{array}$} \\
\hline & & pop & capital & wages & level & time & & $t=1$ & $t=5$ & $t=10$ & $t=20$ & $80 \%$ & $90 \%$ & $95 \%$ & $99 \%$ \\
\hline \multirow[t]{3}{*}{ zero } & $\infty$ & & 0.259 & 0.078 & & & 0.093 & 0.645 & 0.771 & 0.863 & 0.948 & 6.3 & 13.2 & 20.4 & 37.4 \\
\hline & 1.32 & -0.002 & 0.263 & 0.079 & 0.99 & 17.1 & 0.006 & 0.645 & 0.772 & 0.864 & 0.949 & 6.3 & 13.1 & 20.3 & 37.3 \\
\hline & 1.16 & -0.003 & 0.260 & 0.079 & 0.98 & 16.9 & 0.009 & 0.645 & 0.772 & 0.864 & 0.949 & 6.3 & 13.1 & 20.2 & 37.3 \\
\hline \multirow[t]{3}{*}{ low } & 1.08 & -0.006 & 0.259 & 0.080 & 0.97 & 16.1 & 0.014 & 0.645 & 0.772 & 0.865 & 0.950 & 6.2 & 13.0 & 20.0 & 37.3 \\
\hline & 1.04 & -0.011 & 0.253 & 0.079 & 0.94 & 15.2 & 0.021 & 0.645 & 0.774 & 0.867 & 0.951 & 6.1 & 12.8 & 19.8 & 37.5 \\
\hline & 1.02 & -0.020 & 0.248 & 0.080 & 0.91 & 13.6 & 0.030 & 0.646 & 0.776 & 0.870 & 0.953 & 6.0 & 12.5 & 19.4 & 38.4 \\
\hline \multirow[t]{3}{*}{ base } & 1.01 & -0.035 & 0.240 & 0.083 & 0.86 & 12.0 & 0.040 & 0.647 & 0.781 & 0.876 & 0.955 & 5.8 & 12.0 & 18.9 & 40.7 \\
\hline & 1.005 & -0.061 & 0.229 & 0.087 & 0.80 & 10.0 & 0.047 & 0.649 & 0.789 & 0.883 & 0.956 & 5.4 & 11.4 & 18.5 & 44.1 \\
\hline & 1.0025 & -0.100 & 0.217 & 0.095 & 0.74 & 8.4 & 0.052 & 0.654 & 0.802 & 0.892 & 0.955 & 4.9 & 10.7 & 18.5 & 46.4 \\
\hline \multirow[t]{2}{*}{ high } & 1.00125 & -0.159 & 0.204 & 0.109 & 0.68 & 6.9 & 0.054 & 0.661 & 0.818 & 0.899 & 0.953 & 4.4 & 10.1 & 19.0 & 47.4 \\
\hline & 1.000625 & -0.246 & 0.193 & 0.132 & 0.63 & 5.5 & 0.056 & 0.673 & 0.834 & 0.903 & 0.951 & 3.7 & 9.6 & 19.7 & 47.7 \\
\hline
\end{tabular}

C. High Capital Mobility $\left(q_{K}^{*}=1.14\right)$, Narrow Capital Share $(\alpha=0.30)$

\begin{tabular}{|c|c|c|c|c|c|c|c|c|c|c|c|c|c|c|c|}
\hline \multirow{3}{*}{$\begin{array}{c}(1) \\
\text { labor } \\
\text { mobility }\end{array}$} & \multirow{3}{*}{$\begin{array}{c}(2) \\
\text { labor } \\
\text { friction } \\
(\omega)\end{array}$} & & (4) & (5) & (6) & & \multirow{3}{*}{$\begin{array}{c}(8) \\
\text { Cnvrg } \\
\text { Speed } \\
t=\infty\end{array}$} & (9) & (10) & (11) & (12) & (13) & (14) & (15) & (16) \\
\hline & & \multicolumn{3}{|c|}{$\begin{array}{l}\text { Initial Growth Rates } \\
\qquad(\text { at } \mathrm{t}=0)\end{array}$} & \multicolumn{2}{|c|}{$\begin{array}{l}\text { Population } \\
\text { Minimum }\end{array}$} & & \multicolumn{4}{|c|}{$\begin{array}{c}\text { Relative Wage at Time } \\
\text { (in years) }\end{array}$} & \multicolumn{4}{|c|}{$\begin{array}{l}\text { Time to Reach } \\
\text { Relative Wage }\end{array}$} \\
\hline & & pop & capital & wages & level & time & & $t=1$ & $t=5$ & $t=10$ & $t=20$ & $80 \%$ & $90 \%$ & $95 \%$ & $99 \%$ \\
\hline \multirow[t]{3}{*}{ zero } & $\infty$ & & 0.483 & 0.145 & & & 0.175 & 0.678 & 0.854 & 0.942 & 0.990 & 3.4 & 7.0 & 10.9 & 19.9 \\
\hline & 1.32 & -0.001 & 0.489 & 0.147 & 1.00 & 9.4 & 0.006 & 0.678 & 0.854 & 0.942 & 0.990 & 3.4 & 7.0 & 10.8 & 19.9 \\
\hline & 1.16 & -0.002 & 0.487 & 0.147 & 0.99 & 9.7 & 0.009 & 0.678 & 0.854 & 0.942 & 0.990 & 3.4 & 7.0 & 10.8 & 19.9 \\
\hline \multirow[t]{3}{*}{ low } & 1.08 & -0.004 & 0.485 & 0.147 & 0.99 & 9.8 & 0.015 & 0.678 & 0.855 & 0.942 & 0.990 & 3.3 & 7.0 & 10.8 & 19.8 \\
\hline & 1.04 & -0.007 & 0.489 & 0.149 & 0.98 & 9.6 & 0.023 & 0.679 & 0.855 & 0.943 & 0.990 & 3.3 & 7.0 & 10.7 & 19.8 \\
\hline & 1.02 & -0.013 & 0.478 & 0.147 & 0.96 & 9.0 & 0.034 & 0.679 & 0.856 & 0.944 & 0.990 & 3.3 & 6.9 & 10.6 & 19.7 \\
\hline \multirow[t]{3}{*}{ base } & 1.01 & -0.025 & 0.476 & 0.150 & 0.93 & 8.1 & 0.049 & 0.679 & 0.859 & 0.946 & 0.990 & 3.3 & 6.8 & 10.5 & 19.8 \\
\hline & 1.005 & -0.044 & 0.461 & 0.152 & 0.89 & 7.2 & 0.066 & 0.681 & 0.863 & 0.948 & 0.990 & 3.2 & 6.6 & 10.2 & 20.2 \\
\hline & 1.0025 & -0.078 & 0.443 & 0.156 & 0.84 & 6.2 & 0.083 & 0.684 & 0.869 & 0.951 & 0.988 & 3.0 & 6.3 & 9.9 & 21.4 \\
\hline \multirow[t]{2}{*}{ high } & 1.00125 & -0.132 & 0.426 & 0.167 & 0.78 & 5.1 & 0.095 & 0.689 & 0.878 & 0.952 & 0.987 & 2.8 & 6.0 & 9.7 & 22.9 \\
\hline & 1.000625 & -0.212 & 0.397 & 0.182 & 0.72 & 4.3 & 0.102 & 0.697 & 0.888 & 0.952 & 0.985 & 2.6 & 5.6 & 9.7 & 24.0 \\
\hline
\end{tabular}




\section{Table 1: Factor Mobility and Income Convergence (continued)}

Numerical results for a negative capital shock that drops wages to $60 \%$ of their steady-state level. For broad capital share, $(\alpha=0.60)$, per capita capital stock drops to $42.7 \%$ of its steady-state level.

D. Low Capital Mobility $\left(q_{k}{ }^{*}=3.24\right)$, Broad Capital Share $(\alpha=0.60)$

\begin{tabular}{|c|c|c|c|c|c|c|c|c|c|c|c|c|c|c|c|}
\hline \multirow{3}{*}{$\begin{array}{c}(1) \\
\text { labor } \\
\text { mobility }\end{array}$} & \multirow{3}{*}{$\begin{array}{c}(2) \\
\text { labor } \\
\text { friction } \\
(\omega)\end{array}$} & (3) & (4) & (5) & (6) & (7) & \multirow{3}{*}{$\begin{array}{c}(8) \\
\text { Cnvrg } \\
\text { Speed } \\
t=\infty\end{array}$} & (9) & (10) & (11) & (12) & (13) & (14) & (15) & (16) \\
\hline & & \multicolumn{3}{|c|}{$\begin{array}{l}\text { Initial Growth Rates } \\
\qquad(\text { at } \mathrm{t}=0)\end{array}$} & \multicolumn{2}{|c|}{$\begin{array}{l}\text { Population } \\
\text { Minimum }\end{array}$} & & \multicolumn{4}{|c|}{$\begin{array}{l}\text { Relative Wage at Time } \\
\quad \text { (in years) }\end{array}$} & \multicolumn{4}{|c|}{$\begin{array}{l}\text { Time to Reach } \\
\text { Relative Wage }\end{array}$} \\
\hline & & pop & capital & wages & level & time & & $t=1$ & $t=5$ & $\mathrm{t}=10$ & $t=20$ & $80 \%$ & $90 \%$ & $95 \%$ & $99 \%$ \\
\hline \multirow[t]{3}{*}{ zero } & $\infty$ & & 0.043 & 0.026 & & & 0.043 & 0.616 & 0.673 & 0.733 & 0.824 & 17.0 & 33.6 & 50.0 & 87.9 \\
\hline & 1.32 & -0.002 & 0.042 & 0.027 & 0.97 & 36.1 & 0.005 & 0.616 & 0.675 & 0.737 & 0.829 & 16.4 & 32.4 & 48.6 & 84.6 \\
\hline & 1.16 & -0.004 & 0.041 & 0.028 & 0.95 & 33.0 & 0.008 & 0.617 & 0.677 & 0.740 & 0.833 & 15.9 & 31.6 & 47.7 & 92.5 \\
\hline \multirow[t]{3}{*}{ low } & 1.08 & -0.008 & 0.040 & 0.029 & 0.92 & 30.0 & 0.011 & 0.617 & 0.680 & 0.746 & 0.840 & 15.2 & 30.3 & 46.5 & 100.3 \\
\hline & 1.04 & -0.013 & 0.038 & 0.031 & 0.88 & 25.6 & 0.014 & 0.619 & 0.686 & 0.755 & 0.851 & 14.1 & 28.5 & 45.5 & 108.6 \\
\hline & 1.02 & -0.022 & 0.035 & 0.035 & 0.83 & 21.6 & 0.017 & 0.621 & 0.696 & 0.770 & 0.865 & 12.5 & 26.4 & 45.3 & 112.1 \\
\hline \multirow[t]{3}{*}{ base } & 1.01 & -0.037 & 0.034 & 0.042 & 0.79 & 17.9 & 0.019 & 0.625 & 0.712 & 0.791 & 0.879 & 10.7 & 24.2 & 47.2 & 111.0 \\
\hline & 1.005 & -0.058 & 0.032 & 0.054 & 0.75 & 14.4 & 0.020 & 0.632 & 0.733 & 0.815 & 0.890 & 8.9 & 22.4 & 50.2 & 108.2 \\
\hline & 1.0025 & -0.087 & 0.029 & 0.070 & 0.71 & 11.5 & 0.020 & 0.641 & 0.760 & 0.838 & 0.896 & 7.1 & 21.5 & 52.2 & 105.3 \\
\hline \multirow[t]{2}{*}{ high } & 1.00125 & -0.129 & 0.028 & 0.094 & 0.68 & 9.2 & 0.020 & 0.654 & 0.789 & 0.855 & 0.896 & 5.5 & 21.5 & 53.2 & 102.5 \\
\hline & 1.000625 & -0.191 & 0.026 & 0.130 & 0.66 & 7.3 & 0.021 & 0.672 & 0.816 & 0.864 & 0.896 & 4.2 & 21.8 & 53.3 & 98.3 \\
\hline
\end{tabular}

E. Base Capital Mobility $\left(q_{K}^{*}=1.56\right)$, Broad Capital Share $(\alpha=0.60)$

\begin{tabular}{|c|c|c|c|c|c|c|c|c|c|c|c|c|c|c|c|}
\hline \multirow{3}{*}{$\begin{array}{c}(1) \\
\text { labor } \\
\text { mobility }\end{array}$} & \multirow{3}{*}{$\begin{array}{l}(2) \\
\text { labor } \\
\text { friction } \\
(\omega)\end{array}$} & (3) & (4) & (5) & (6) & & \multirow{3}{*}{$\begin{array}{c}(8) \\
\text { Cnvrg } \\
\text { Speed } \\
t=\infty\end{array}$} & (9) & (10) & (11) & (12) & (13) & (14) & (15) & (16) \\
\hline & & \multicolumn{3}{|c|}{$\begin{array}{l}\text { Initial Growth Rates } \\
\qquad(\text { at } \mathrm{t}=0)\end{array}$} & \multicolumn{2}{|c|}{$\begin{array}{l}\text { Population } \\
\text { Minimum }\end{array}$} & & \multicolumn{4}{|c|}{$\begin{array}{l}\text { Relative Wage at Time } \\
\quad \text { (in years) }\end{array}$} & \multicolumn{4}{|c|}{$\begin{array}{l}\text { Time to Reach } \\
\text { Relative Wage }\end{array}$} \\
\hline & & pop & capital & wages & level & time & & $t=1$ & $t=5$ & $\mathrm{t}=10$ & $t=20$ & $80 \%$ & $90 \%$ & $95 \%$ & $99 \%$ \\
\hline \multirow[t]{3}{*}{ zero } & $\infty$ & & 0.068 & 0.041 & & & 0.068 & 0.625 & 0.711 & 0.792 & 0.894 & 10.6 & 20.9 & 31.1 & 54.8 \\
\hline & 1.32 & -0.002 & 0.068 & 0.042 & 0.98 & 23.6 & 0.005 & 0.625 & 0.712 & 0.795 & 0.896 & 10.4 & 20.5 & 30.6 & 54.8 \\
\hline & 1.16 & -0.003 & 0.068 & 0.043 & 0.97 & 22.9 & 0.009 & 0.626 & 0.714 & 0.796 & 0.898 & 10.3 & 20.3 & 30.3 & 55.0 \\
\hline \multirow[t]{3}{*}{ low } & 1.08 & -0.006 & 0.067 & 0.044 & 0.95 & 21.2 & 0.013 & 0.626 & 0.716 & 0.800 & 0.902 & 10.0 & 19.8 & 29.7 & 56.0 \\
\hline & 1.04 & -0.011 & 0.065 & 0.046 & 0.92 & 19.5 & 0.018 & 0.627 & 0.720 & 0.806 & 0.907 & 9.6 & 19.0 & 28.8 & 59.3 \\
\hline & 1.02 & -0.020 & 0.062 & 0.049 & 0.88 & 17.1 & 0.024 & 0.629 & 0.728 & 0.817 & 0.915 & 8.9 & 17.8 & 27.8 & 66.4 \\
\hline \multirow[t]{3}{*}{ base } & 1.01 & -0.034 & 0.059 & 0.055 & 0.84 & 14.2 & 0.028 & 0.633 & 0.741 & 0.832 & 0.923 & 8.0 & 16.4 & 27.1 & 71.4 \\
\hline & 1.005 & -0.054 & 0.055 & 0.066 & 0.79 & 11.7 & 0.031 & 0.638 & 0.760 & 0.851 & 0.928 & 6.9 & 14.9 & 27.3 & 72.4 \\
\hline & 1.0025 & -0.086 & 0.051 & 0.082 & 0.75 & 9.5 & 0.032 & 0.647 & 0.784 & 0.869 & 0.930 & 5.7 & 13.5 & 28.5 & 71.8 \\
\hline \multirow[t]{2}{*}{ high } & 1.00125 & -0.129 & 0.048 & 0.106 & 0.71 & 7.7 & 0.033 & 0.660 & 0.811 & 0.883 & 0.929 & 4.6 & 12.5 & 29.9 & 71.0 \\
\hline & 1.000625 & -0.192 & 0.045 & 0.142 & 0.68 & 6.1 & 0.034 & 0.678 & 0.836 & 0.890 & 0.927 & 3.6 & 12.0 & 30.6 & 69.9 \\
\hline
\end{tabular}

F. High Capital Mobility $\left(q_{\mathrm{K}}{ }^{*}=1.14\right)$, Broad Capital Share $(\alpha=0.60)$

\begin{tabular}{|c|c|c|c|c|c|c|c|c|c|c|c|c|c|c|c|}
\hline \multirow{3}{*}{$\begin{array}{c}(1) \\
\text { labor } \\
\text { mobility }\end{array}$} & \multirow{3}{*}{$\begin{array}{c}(2) \\
\text { labor } \\
\text { friction } \\
(\omega)\end{array}$} & (3) & (4) & (5) & (6) & (7) & \multirow{3}{*}{$\begin{array}{c}(8) \\
\text { Cnvrg } \\
\text { Speed } \\
t=\infty\end{array}$} & (9) & (10) & (11) & (12) & (13) & (14) & (15) & (16) \\
\hline & & \multicolumn{3}{|c|}{$\begin{array}{l}\text { Initial Growth Rates } \\
\quad(\text { at } \mathrm{t}=0)\end{array}$} & \multicolumn{2}{|c|}{$\begin{array}{l}\text { Population } \\
\text { Minimum }\end{array}$} & & \multicolumn{4}{|c|}{$\begin{array}{l}\text { Relative Wage at Time } \\
\text { (in years) }\end{array}$} & \multicolumn{4}{|c|}{$\begin{array}{l}\text { Time to Reach } \\
\text { Relative Wage }\end{array}$} \\
\hline & & pop & capital & wages & level & time & & $t=1$ & $\mathrm{t}=5$ & $\mathrm{t}=10$ & $t=20$ & $80 \%$ & $90 \%$ & $95 \%$ & $99 \%$ \\
\hline \multirow[t]{3}{*}{ zero } & $\infty$ & & 0.128 & 0.077 & & & 0.130 & 0.646 & 0.786 & 0.887 & 0.969 & 5.5 & 11.0 & 16.3 & 28.8 \\
\hline & 1.32 & -0.001 & 0.132 & 0.080 & 0.99 & 13.3 & 0.006 & 0.647 & 0.786 & 0.888 & 0.969 & 5.5 & 10.9 & 16.2 & 28.6 \\
\hline & 1.16 & -0.002 & 0.130 & 0.080 & 0.99 & 13.2 & 0.009 & 0.647 & 0.787 & 0.888 & 0.970 & 5.5 & 10.9 & 16.2 & 28.6 \\
\hline \multirow[t]{3}{*}{ low } & 1.08 & -0.004 & 0.131 & 0.081 & 0.98 & 13.1 & 0.014 & 0.647 & 0.788 & 0.890 & 0.970 & 5.4 & 10.8 & 16.0 & 28.5 \\
\hline & 1.04 & -0.008 & 0.128 & 0.081 & 0.96 & 12.5 & 0.022 & 0.648 & 0.790 & 0.892 & 0.971 & 5.4 & 10.6 & 15.8 & 28.5 \\
\hline & 1.02 & -0.014 & 0.124 & 0.083 & 0.94 & 11.3 & 0.031 & 0.649 & 0.795 & 0.896 & 0.973 & 5.2 & 10.3 & 15.4 & 28.8 \\
\hline \multirow[t]{3}{*}{ base } & 1.01 & -0.025 & 0.120 & 0.087 & 0.91 & 10.1 & 0.042 & 0.651 & 0.802 & 0.903 & 0.974 & 4.9 & 9.8 & 14.8 & 30.1 \\
\hline & 1.005 & -0.044 & 0.115 & 0.095 & 0.87 & 8.7 & 0.052 & 0.655 & 0.814 & 0.912 & 0.974 & 4.5 & 9.1 & 14.2 & 33.1 \\
\hline & 1.0025 & -0.072 & 0.108 & 0.108 & 0.82 & 7.1 & 0.059 & 0.663 & 0.831 & 0.921 & 0.972 & 4.0 & 8.3 & 13.7 & 36.0 \\
\hline \multirow[t]{2}{*}{ high } & 1.00125 & -0.118 & 0.102 & 0.132 & 0.78 & 5.9 & 0.063 & 0.674 & 0.851 & 0.928 & 0.969 & 3.4 & 7.5 & 13.7 & 37.5 \\
\hline & 1.000625 & -0.179 & 0.095 & 0.164 & 0.74 & 4.9 & 0.065 & 0.690 & 0.871 & 0.930 & 0.967 & 2.8 & 6.7 & 14.1 & 38.1 \\
\hline
\end{tabular}


Figure 1: Time-Series Response to a Negative Capital Shock

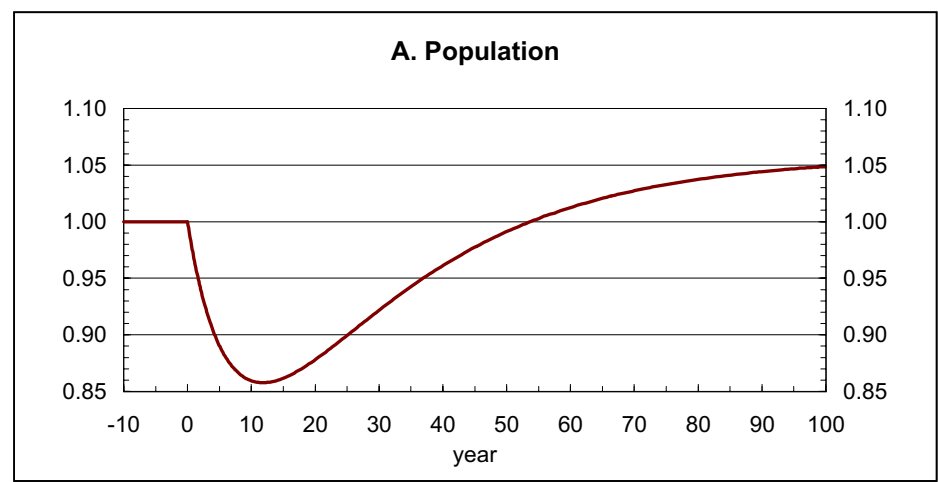

B. Relative Wages

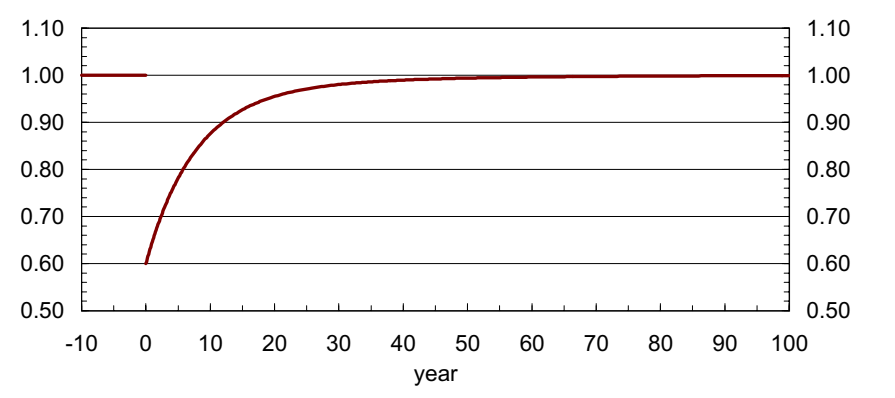

C. Relative Sales and Rental Price of Housing

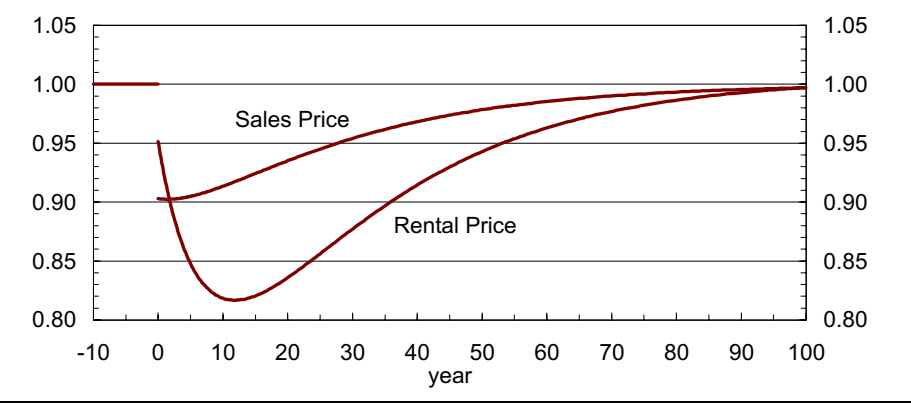

D. Convergence Speed

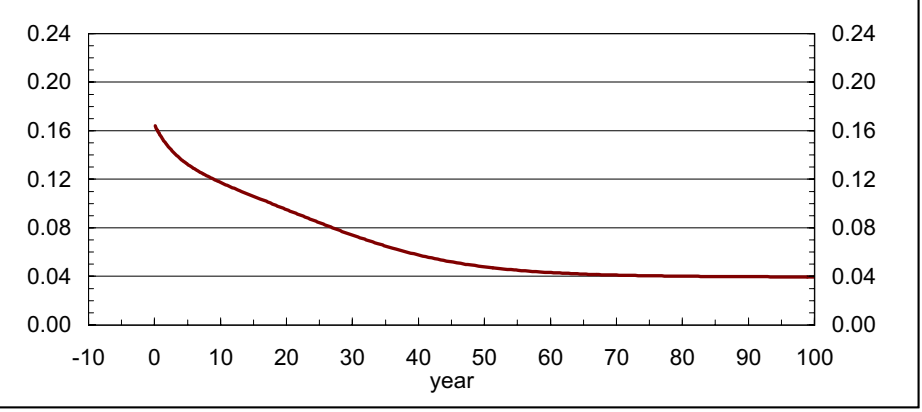

\section{Exogenous Parameters}

Figure assumes a shock which reduces initial physical capital stock such that income is at $60 \%$ of its steady-state level

Capital Share

$\alpha=0.30$

Capital Depreciation Rate

$\delta=0.05$

Housing Share

$\zeta=0.20$

Time Preference

$\rho=0.02$

Technological Progress

$x=0.02$

Steady-State Shadow

Value of Capital

$\mathrm{q}_{\mathrm{K}}{ }^{\star}=1.56$

Relative Wealth to Induce

$1 \%$ Net Migration Rate

$\omega=1.01$

\section{Endogenous Results}

\begin{tabular}{|c|c|c|}
\hline $\begin{array}{c}\text { Initial Relative } \\
\text { House Sales Price }\end{array}$ & value $=$ & 0.903 \\
\hline Initial Net Migration & $\gamma_{\mathrm{L}}=$ & -0.035 \\
\hline $\begin{array}{l}\text { Initial Rate } \\
\text { oss Capital Formation }\end{array}$ & $\gamma_{\mathrm{K}}=$ & 0.240 \\
\hline Initial Income Growth & $\gamma_{\mathrm{w}}=$ & 0.083 \\
\hline $\begin{array}{c}\text { Minimum } \\
\text { Population Density }\end{array}$ & $\mathrm{L}_{\min }=$ & 0.858 \\
\hline $\begin{array}{l}\text { Steady-State Relative } \\
\text { Population Density }\end{array}$ & $L^{*}=$ & 1.058 \\
\hline $\begin{array}{l}\text { Steady-State Relative } \\
\text { Asset Wealth }\end{array}$ & $\operatorname{assts} *=$ & 0.447 \\
\hline $\begin{array}{c}\text { Asymptotic } \\
\text { Convergence Speed }\end{array}$ & $\Lambda^{*}=$ & 0.0 \\
\hline
\end{tabular}


Figure 2: High Versus Low Labor Mobility and Income Shocks
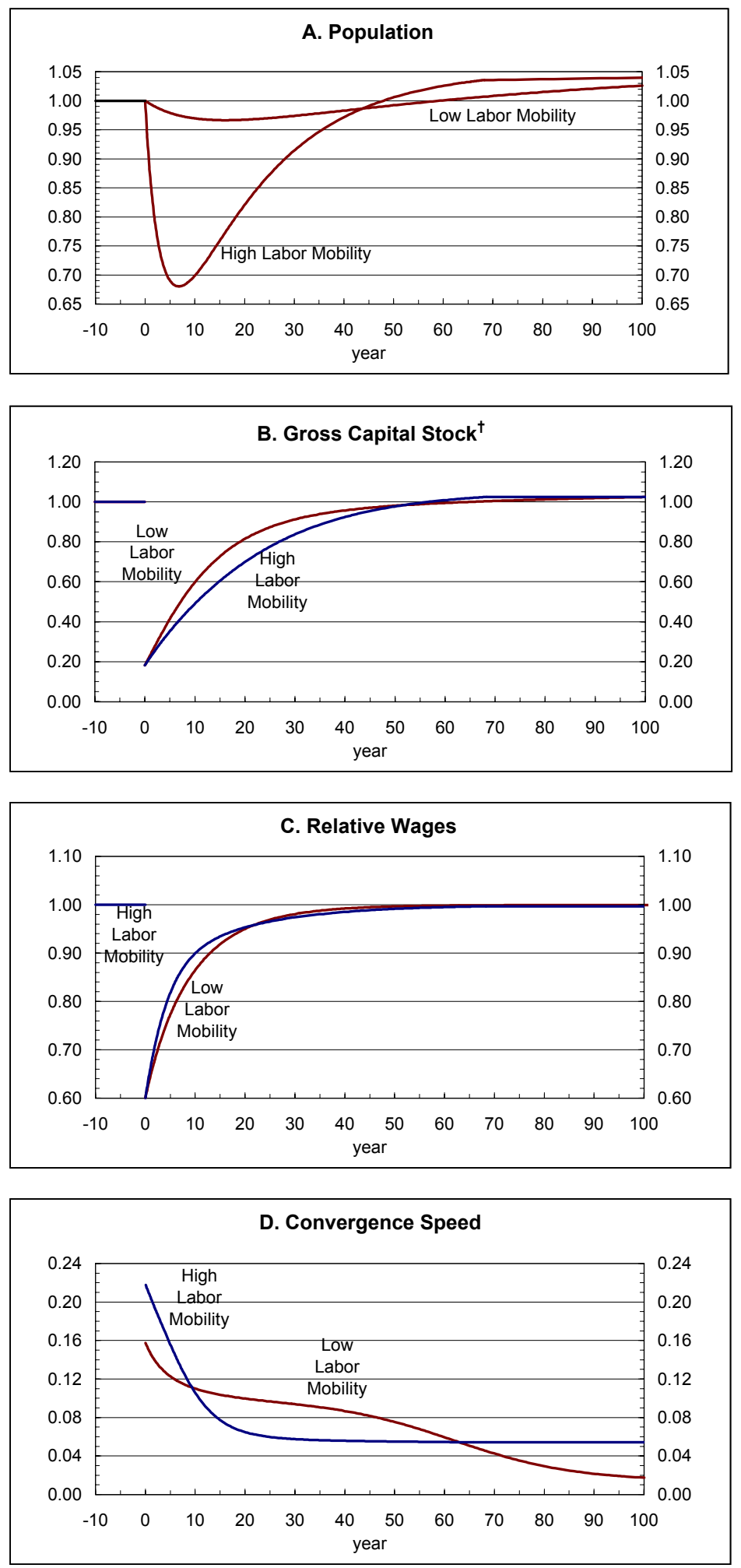

\section{Exogenous Parameters}

Figure assumes a shock which reduces initial physical capital stock such that income is at $60 \%$ of its steady-state level. Unless otherwise noted, parameters are the same as in Figure 1.

$$
\begin{array}{ll}
\begin{array}{c}
\text { Relative Wealth to } \\
\text { induce } 1 \% \text { Net }
\end{array} & \omega_{\text {Low }}=1.08000 \\
\text { Migration Rate } & \omega_{\text {High }}=1.00125
\end{array}
$$

\begin{tabular}{|c|c|c|}
\hline Initial Relative & Value $_{\text {Low }}$ & 0.936 \\
\hline House Sales Price & value $_{\text {High }}$ & 0.863 \\
\hline \multirow{2}{*}{ Initial Net Migration } & $\gamma_{\mathrm{L}, \text { Low }}$ & $=-0.006$ \\
\hline & $\gamma_{\mathrm{L}, \mathrm{High}}$ & $=-0.159$ \\
\hline \multirow{2}{*}{$\begin{array}{l}\text { Initial Gross Capital } \\
\text { Formation }\end{array}$} & $\gamma_{\mathrm{K}, \text { Low }}$ & 0.259 \\
\hline & $\gamma_{K, \text { High }}$ & 0.204 \\
\hline \multirow[t]{2}{*}{ nitial Income Growth } & $\gamma_{w, \text { Low }}$ & 0.080 \\
\hline & $\gamma_{\mathrm{w}, \mathrm{High}}$ & 0.109 \\
\hline \multirow{2}{*}{$\begin{array}{l}\text { Minimum Population } \\
\text { Density }\end{array}$} & $\mathrm{L}_{\text {min, Low }}$ & 0.966 \\
\hline & $\mathrm{L}_{\min , \mathrm{High}}$ & 0.680 \\
\hline teady-State Relative & $\mathrm{L}^{\star}{ }_{\text {Low }}$ & 1.060 \\
\hline Population Density & $\mathrm{L}^{*}{ }_{\mathrm{High}}$ & 1.053 \\
\hline \multirow{2}{*}{$\begin{array}{l}\text { teady-State Relative } \\
\text { Asset Wealth }\end{array}$} & $\operatorname{assts}^{*}{ }_{\text {Low }}$ & 0.428 \\
\hline & $\operatorname{assts}^{*}{ }_{\mathrm{High}}$ & 0.491 \\
\hline \multirow{2}{*}{$\begin{array}{c}\text { Asymptotic } \\
\text { Convergence Speed }\end{array}$} & $\Lambda *_{\text {Low }}$ & 0.014 \\
\hline & $\Lambda^{*}{ }_{\text {High }}$ & 0.054 \\
\hline
\end{tabular}

\section{Endogenous Results}

† In Panel B, gross capital stock is normalized by the level of technological progress, $e^{x t}$ 
Figure 3: Factor Mobility and Income Convergence

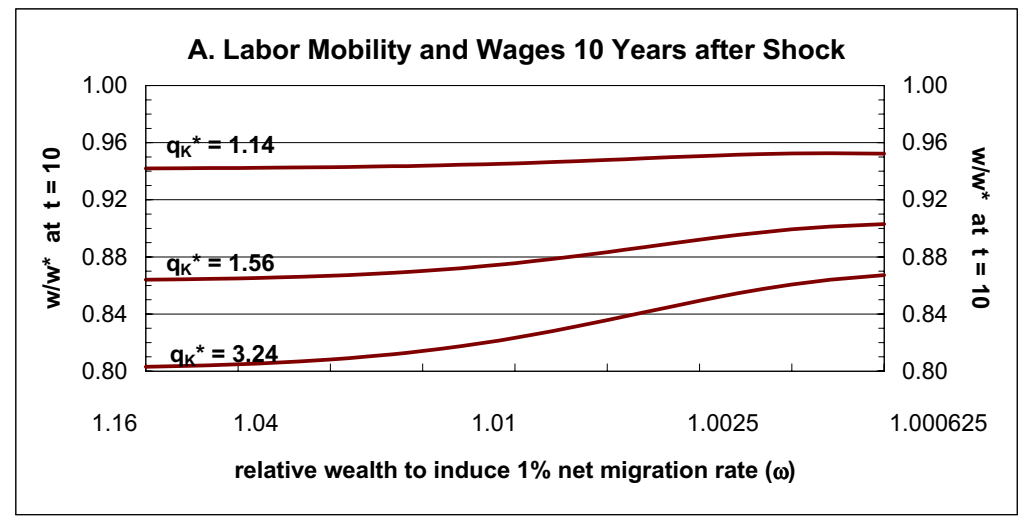

B. Capital Mobility and Wages 10 Years after Shock
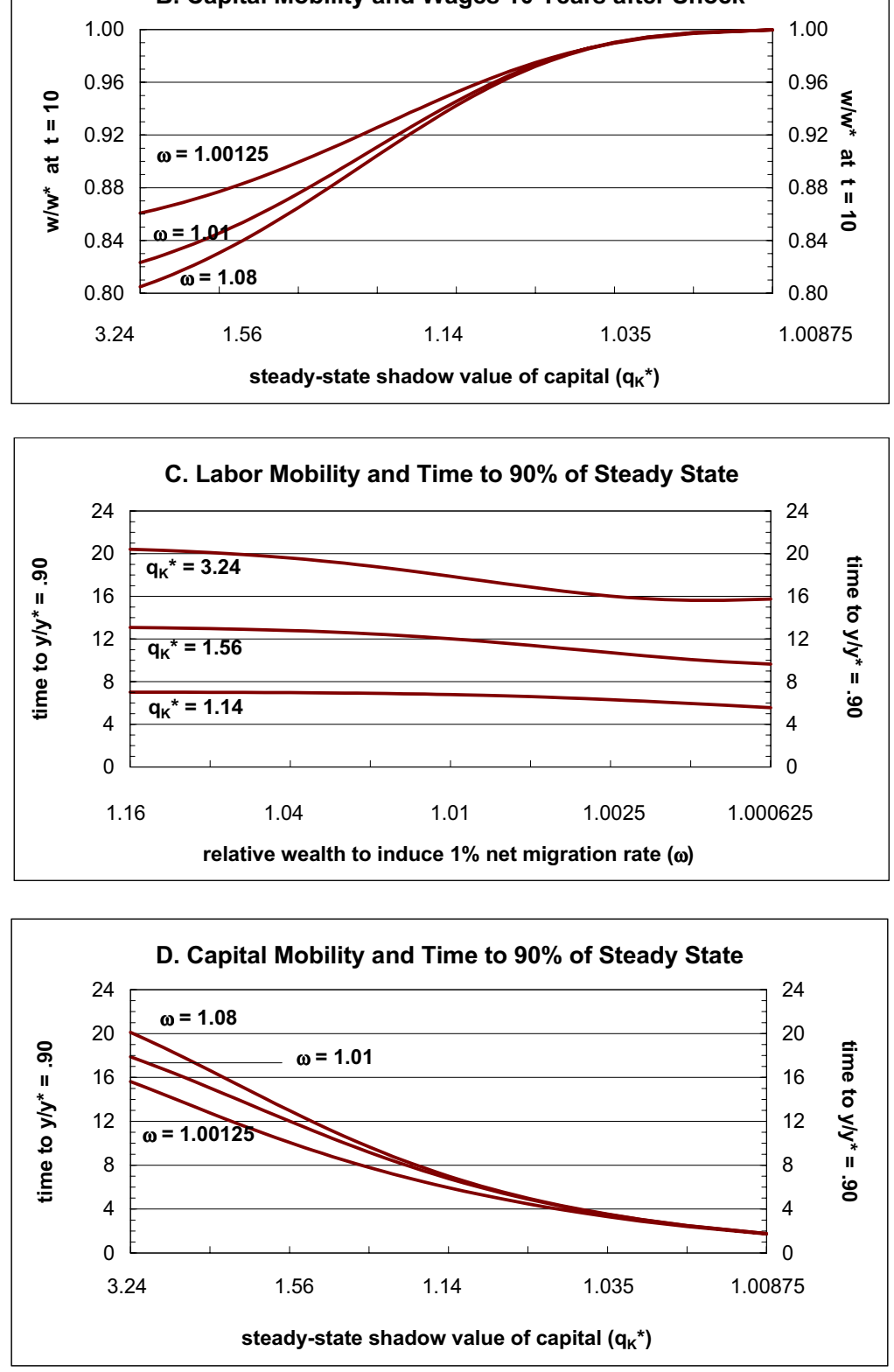

\section{Exogenous Parameters}

Figure assumes a shock which reduces initial physical capital stock such that income is at $60 \%$ of its steady-state level. Except for factor mobility as listed in each panel, parameters are the same as in Figure 1. 